\title{
Chapter 5 \\ Violence in the Balkans: Regional \\ Commons and Country Specifics
}

\begin{abstract}
This chapter presents first findings from the BHS by providing data on main incident, offender, victim, and procedural characteristics of (lethal) violence in six countries of Southeastern Europe and the Balkans: Croatia, Hungary, Kosovo, North Macedonia, Romania, and Slovenia. The discussion will concentrate on regional commons, as well as country specifics with a particular focus on comparison between completed and attempted homicides. In terms of the type of violence, only the most relevant ones will be analyzed, whereby this relates to both the most prevalent and most interesting for the regional context. Thus, certain methodological aspects, like those related to missing data and the merging of datasets with different counting units, will be presented. Bearing in mind the overall scope of the BHS with more than 200 different variables, this chapter clearly presents but a fraction of all findings. Nevertheless, it is a solid starting point for future topic-wise more focused in-depth analyses, and will hopefully deliver food for thought on new lines of (lethal) violence and homicide research.
\end{abstract}

Keywords Missing data in violence research - Non-lethal violence vs. homicides · Violent incident characteristics · Victims of violence characteristics $\cdot$ Violent offender characteristics · (Lethal) violence prosecution

Taking into account the BHS's methodological context (Chap. 4) and its relevance for an informed and critical consumption of the study's data, in Sect. 5.1 main incident characteristics are presented. This is done by focusing on regional commons and country specifics, on the one hand, and with regard to commons and specifics of completed and attempted homicides, on the other hand. In Sect. 5.2, the main offender characteristics are presented, whereas in Sect. 5.3, victim characteristics, are discussed, both again focusing on regional commons and country specifics, thus contrasting completed and attempted homicides, or to be more exact, lethal and non-lethal violence. The BHS findings will also be discussed in view of prior homicide research findings.

Now, it is frequent in homicide research that only (completed) homicides are analyzed as one category, so for example in UNODC's Global Homicide Study (Global Study on Homicide, 2019) or the European Homicide Monitor. This makes 
sense from a pragmatic and practical, methodological, and even conceptual perspective, especially if homicides are considered to be essentially different phenomena than non-lethal violence (attempted homicides). However, the BHS takes a different approach and questions this assumption all together by presuming that there might be no essential difference in attempted and completed homicides, besides the obvious - the death of the victim. This perspective is partly rooted in a normative understanding of the concept of "attempt" in relation to homicide, which implies that the offender intended to kill the victim or negligently accepted the possibility of such an outcome and set in motion all necessary steps for this to occur, but that due to some event or action or pure luck, the victim did not die. Now, such normative perspective on "attempt" is clearly a consequence of the BHS being a case-file based study that sources its data from the criminal justice system which operates on the basis of normative constructs. By looking at the phenomenological features of attempted (non-lethal) and completed (lethal) homicide cases in the BHS sample, as we shall see throughout this chapter, first findings indicate that it might very well be a meaningful approach to look at attempted and completed homicide cases holistically, as one category or phenomenon.

While the first three sections of this chapter relate to the BHS's second line of inquiry about the criminological realities of (lethal) violence, Sect. 5.4 contains essential findings on how (lethal) violence is dealt with by the criminal justice system. This includes not only various procedural characteristics of criminal prosecutions and trials but also relevant outcomes and sentencing decisions. These findings relate to the BHS's first line of inquiry about the social and normative construction of (lethal) violence.

Now, the missing data challenge in homicide research is neither new nor unique to the BHS, and it would surely deserve a chapter of its own. ${ }^{1}$ However, due to the condensed publication format, the missing data issue in the BHS will be briefly discussed at the outset of each section and limited to depicting the scope of missing data as relevant for each section. For a full overview of the scope of missing data by single variable and BHS country, see Appendix. If not indicated otherwise, the presented data excludes missing variables (dropping variables). Although such an approach clearly contains the risk of distorting results, by presenting the scope of the missing data problem transparently, it will at least be possible to objectively assess the magnitude of the potential result distortion. This then indicates the level of cautiousness with which the different results should be interpreted. Since there is no generally accepted rule of thumb when it comes to missing data from criminological case file analysis, one needs to make a critical assessment both on the scope of missing data and on the type of variable in question. Considering that "the only really good solution to the missing data problem is not to have any" (cit.

\footnotetext{
${ }^{1}$ See, for example, the 2004 thematic issue (3) of the Homicide Studies and, in particular, the overview provided by Riedel and Regoeczi (2004) or Liem in Chap. 2. Although the papers in the aforementioned special issue deal almost exclusively with the challenge of missing data in homicide research that is based on statistical datasets (not case file analysis), they provide a concise overview of the complexity and relevance of the issue at hand.
} 
Allison, 2002, p. 2), the sectional discussions of the BHS's missing data occurrences also aim at improving our understanding of how and why data is missing in case file analysis. In that sense, these discussions are as much a snapshot of lessons learned, as they are extremely valuable insights into the missing data phenomenon in case file-based violence research.

\subsection{Incident Characteristics}

While puzzling about (lethal) violence in the Balkans, one of the core questions we asked ourselves was "what kind of violence appears in this region of Europe?" This question has been triggered by what I deemed the Balkan-violence-paradox (Chap. 1). This paradox denotes a somewhat strange situation in which we notice higher homicide rates throughout Southeastern Europe in comparison to Central and Western Europe. At the same time, there is solid evidence that, compared to other parts of Europe, the Balkans do not fit the profile of a high crime region and appear to be much safer in terms of street and urban crime. Now, in terms of the BHS, this paradox should be reflected at least by rather low levels of crime-related (lethal) violence. The question at hand is, what other types of (lethal) violence seem to occur more frequently in the region, and how this might be explained?

\subsubsection{Missing Incident Data}

Analyzing the BHS's incident variables (counting unit: case), the scope of the missing data problem is mostly insignificant. The majority of variables display a share of less than 1-2\% of missing data. The variables capturing a sexual connotation of the incident or cruel mode of perpetration display less than $5 \%$ of missing data, as do variables on the time of the incident. When classifying the incident as affective (non-premeditated), a more significant share of missing data appears (13\%), as does in the case of determining the exact location in which the incident ended (20\%). Interestingly, when it comes to the data on the location the incident started in, the misses are insignificant $(0.3 \%)$. This might indicate that the data on the incident's ending location is not contained in the case files. Or that the variables distinguishing the incident's starting and ending location should be reconsidered, perhaps even be merged into one single variable in the future. For a full overview of the missingness in the BHS datasets, see Appendix.

A main initial concern for the BHS was the short case description variable. However, this has only $4 \%$ of missing entries (no case description at all), while approximately $25 \%$ of the case descriptions were of poor quality and needed to be supplemented manually by feeding in data from relevant other variables and databases (offender, victim, and victim-offender relationship database). With regard to distinguishing between completed and attempted homicides (as expected), there are no missing data. Nevertheless, as soon as one looks at the variables dealing with specific normative qualifications of the incidents, the missings increase significantly. 


\subsubsection{Attempted vs. Completed Homicides}

Considering that an attempted crime (in legal terms, at least) means that the offender has taken all the steps necessary for the crime to be completed, it is quite dubious when homicide research relying on data sourced from the criminal justice system does not include attempted but only completed homicides. Clearly, there are valid pragmatic, practical, methodological, and even conceptual arguments in favor of such an approach, but at least the conceptual ones seem rather weak. The non-lethal outcome of a violent incident might be due to good or bad fortune of the victim, third-party intervention (or not), or a matter of the incident's micro-location. When discussing the matter of (lethal) injuries with forensic doctors, one quickly learns that an offender with a clear homicidal intent, aiming and shooting at the head of a victim, might thereby undeliberately cause only a flesh wound to the victim's neck, leaving the victim with a non-life-threatening injury and a scar. Another offender, lacking a homicidal intent, might aim and shoot at a victim's leg and, in case the bullet hits the leg's artery, undeliberately cause the victim's quick death. Neither conceptually, nor criminologically speaking, does it appear plausible or even justifiable to exclude the first scenario from a homicide study, based solemnly on the fact that the victim did not die (as intended).

Clearly, the question of a (non)lethal violent incident's "homicidality" is crucial for homicide research, and just as clearly neither strictly including nor strictly excluding all attempted homicides is the best solution. Perhaps we ought to think about "homicidality" more intensively in terms of varying degrees and sliding scales and less in terms of exact dichotomies like "attempted" and "completed" or "excluding" and "including." At least on first thought there seems to be no sensible reason for expecting a strikingly different incident constellation, or specific offender and victim profiles with regard to lethal and non-lethal homicidal violence. But even if there were, one would have to look at these cases of non-lethal violence and compare them to the lethal ones in order to be sure and identify potential differences, which is exactly what we will do in the next few paragraphs.

The BHS has analyzed $42 \%$ completed and 58\% attempted homicide cases $\left(\mathrm{N}_{\text {lethal }}\right.$ $847 ; \mathrm{N}_{\text {non-lethal }} 1150$ ). Such an approximate $40 / 60$ ratio of completed vs. attempted homicides in the total sample corresponds well to the country level in the case of Croatia (34/64; $\mathrm{N}_{\text {lethal }} 186 ; \mathrm{N}_{\text {non-lethal }} 333$ ), Kosovo (36/64; $\left.\mathrm{N}_{\text {lethal }} 26 ; \mathrm{N}_{\text {non-lethal }} 47\right)$, Romania (34/66; $\left.\mathrm{N}_{\text {lethal }} 191 ; \mathrm{N}_{\text {non-lethal }} 379\right)$ and more or less Slovenia $\left(45 / 55 ; \mathrm{N}_{\text {lethal }}\right.$ $60 ; \mathrm{N}_{\text {non-lethal }}$ 73), whereas it is inverted in case of North Macedonia (57/43; $\mathrm{N}_{\text {lethal }} 55$; $\left.\mathrm{N}_{\text {non-lethal }} 41\right)$ and Hungary $\left(54 / 46 ; \mathrm{N}_{\text {lethal }} 329 ; \mathrm{N}_{\text {non-lethal }} 277\right)$ with more completed than attempted homicides. Due to no missing data on the competed-attempted variable and a quite comparable (or at least not dramatically different) ratio between completed and attempted homicides, the incident variables are analyzed with regard to the total sample in the next steps.

Bearing in mind the aforementioned 40/60 ratio of completed vs. attempted homicides, there are no major differences between completed and attempted homicides in the BHS sample when it comes to the distribution pattern of different characteristics within the following variables (Table 5.1): 
Table 5.1 Similarities between completed and attempted homicides - distribution patterns of different characteristics within incident variables (counting unit: case; N 1997) ${ }^{\mathrm{a}}$

\begin{tabular}{|c|c|c|c|}
\hline Variable & Value & $\%$ Completed & $\%$ Attempted \\
\hline \multirow{3}{*}{$\begin{array}{l}\text { Incident place } \\
\left(\mathrm{N}_{\text {valid }} 1,976\right)\end{array}$} & rural & 46.4 & 43.2 \\
\hline & urban & 37.7 & 35.1 \\
\hline & capital & 15.9 & 21.7 \\
\hline \multirow{3}{*}{$\begin{array}{l}\text { Incident location } \\
\left(\mathrm{N}_{\text {valid }} 1,994\right)\end{array}$} & private & 74.6 & 66.7 \\
\hline & public & 25.4 & 33.3 \\
\hline & evening & 37.6 & 40.4 \\
\hline \multirow{3}{*}{$\begin{array}{l}\text { Incident time } \\
\left(\mathrm{N}_{\text {valid }} 1,908\right)\end{array}$} & afternoon & 25.6 & 25.7 \\
\hline & night & 21.8 & 20.8 \\
\hline & morning & 15.0 & 13.1 \\
\hline \multirow{7}{*}{$\begin{array}{l}\text { Day of the week } \\
\left(\mathrm{N}_{\text {valid }} 1,994\right)\end{array}$} & Monday & 16.8 & 12.8 \\
\hline & Saturday & 16.2 & 17.7 \\
\hline & Sunday & 15.9 & 17.2 \\
\hline & Friday & 15.6 & 13.8 \\
\hline & Wednesday & 12.7 & 13.3 \\
\hline & Thursday & 12.1 & 12.3 \\
\hline & Tuesday & 10.8 & 13 \\
\hline \multirow{4}{*}{$\begin{array}{l}\text { Number of offenders } \\
\left(\mathrm{N}_{\text {valid }} 1,995\right)\end{array}$} & one & 87.8 & 90.2 \\
\hline & two & 7.6 & 6.3 \\
\hline & three & 3 & 2.3 \\
\hline & four or more & 1.7 & 1.3 \\
\hline \multirow{4}{*}{$\begin{array}{l}\text { Number of victims } \\
\left(\mathrm{N}_{\text {valid }} 1,995\right)\end{array}$} & one & 90.4 & 88.9 \\
\hline & two & 6.9 & 8.3 \\
\hline & three & 1.8 & 1.9 \\
\hline & four or more & 0.9 & 0.9 \\
\hline \multirow{2}{*}{ Sexual $\left(\mathrm{N}_{\text {valid }} 1,903\right)$} & not sex-related & 96 & 99.2 \\
\hline & sex-related & 4 & 0.8 \\
\hline \multirow{2}{*}{ Cruel ( $\left.\mathrm{N}_{\text {valid }} 1,904\right)$} & not cruel & 96.6 & 99.7 \\
\hline & cruel & 3.4 & 0.3 \\
\hline \multirow{2}{*}{ Affective ( $\left.\mathrm{N}_{\text {valid }} 1,735\right)$} & premeditated & 57.2 & 51.4 \\
\hline & affective & 42.6 & 48.6 \\
\hline \multirow{5}{*}{$\begin{array}{l}\text { Main motive } \\
\left(\mathrm{N}_{\text {valid }} 1,997\right)\end{array}$} & unclear & 43.2 & 50.6 \\
\hline & revenge & 25.3 & 27.4 \\
\hline & greed & 16.9 & 9.0 \\
\hline & (self)defense & 5.5 & 5.7 \\
\hline & vigilantism & 3.7 & 3.2 \\
\hline Relationship & non-stranger & 88 & 82.8 \\
\hline$\left(\mathrm{N}_{\text {valid }} 1,966\right)$ & stranger & 12 & 17.2 \\
\hline
\end{tabular}

aThe analysis does not compare the values of the shares as such due to the unequal share of attempted and completed homicides within the overall sample and due to the inverted ratio in the samples from North Macedonia and Hungary. Instead the analysis compares the distribution pattern of different characteristics within each variable differentiating between completed and attempted homicides. The results presented are based on valid cases as provided for each of the variables 
We can observe that the distribution pattern of the different characteristics within each of the variables is the same for completed and attempted homicides (Table 5.1). Even in the case of the variable capturing the day of the week when the incident took place, we see that the distribution/frequency concentrates around the weekend. This is more evident for attempted than for completed homicides, where Saturdays and Sundays are the weekdays with the highest share of incidents. Looking at the completed homicides and their distribution throughout the days of the week, we notice that the concentration around the weekend is more dispersed and also includes Monday and Friday, whereby Monday probably reflects those incidents that took place in the night from Sunday to Monday. However, both completed and attempted homicides are clearly concentrated during/around the weekends. Even in cases of affective or premeditated violence, there appears no difference in the distribution pattern when comparing completed and attempted homicides. Most of all incidents, regardless of their lethality, are premeditated. Even in terms of the main motive, completed and attempted homicides in the BHS sample display an overlapping distribution pattern. Besides the category of unclear motive, which is the most common category for completed as well as attempted homicides, most frequent motives are in both instances revenge, greed, (self)defense, and vigilantism.

There are however noticeable differences between completed and attempted homicides observable in the BHS sample when looking at the characteristics of distribution pattern of incident within the variables victim-offender relationship and type of violence (Fig. 5.1). On first thought, one might assume that the variance in these variables could be under the influence of the incident's micro-location, indicating that homicides committed in a public location are simply more likely to remain attempted than those committed in a private location which more frequently result in the death of the victim. This assumption could not be confirmed based on the first cross-tabulation analysis, and it seems that the incident's micro-location is not an indicator for potential homicide lethality. More elaborate analyses would be needed to confirm these findings.

Clearly, it would be somewhat speculative to conclude at this point and without further in-depth analysis that there is a striking phenomenological difference between completed and attempted homicide incidents. However, the presented results (Table 5.1 and Fig. 5.1) also do not provide solid grounds for stating the opposite, meaning that there is an obvious difference between completed and attempted homicides (besides the obvious fact of the lethal consequence). Despite the results not being fully conclusive with regard to either of the two premises, they seem to be pointing toward the conclusion that (completed) homicides - phenomenologically speaking - might not be a special type of (lethal) violence. At least (completed) homicides in the BHS sample do not appear to be special enough to be studied outside the scope or even by completely disregarding attempted homicides. Now, if homicide research that focuses exclusively on completed homicide incidents is nevertheless considered legit and sound, then at least the same standard applies to homicide research that includes attempted homicides, especially when it comes to those variables that display no significant differences in distribution patterns in case of completed vs. attempted homicides (Table 5.1). 

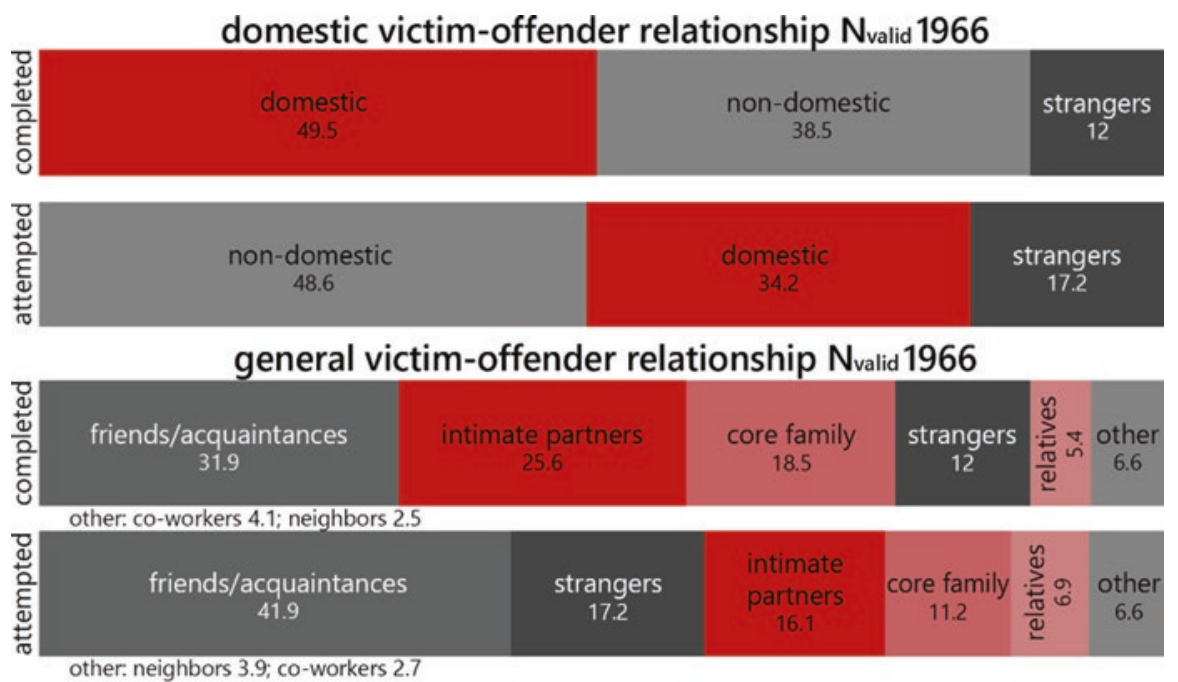

other: neighbors 3.9; co-workers 2.7

\section{type of violence $\mathrm{N}_{\text {valid }} 1995$}

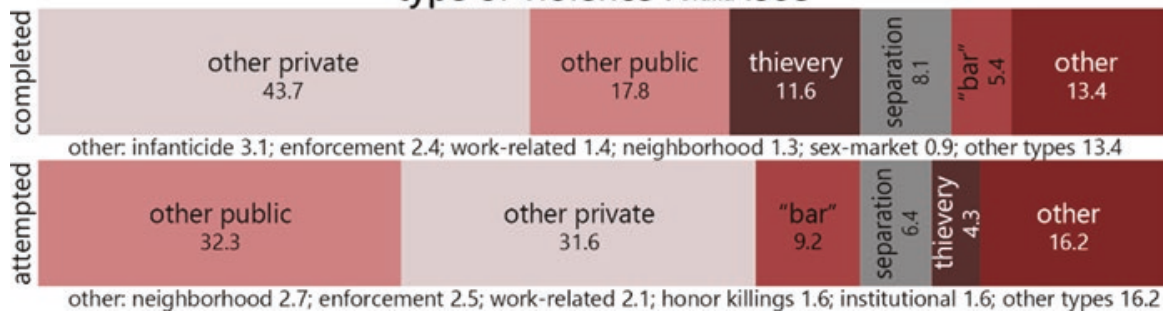

Fig. 5.1 Differences between completed and attempted homicides - distribution patterns of different characteristics within incident variables (counting unit: case; N 1997; in percentages)

\subsubsection{Types of (Non)Lethal Violence}

According to the BHS results presented above (Fig. 5.1), the five most frequent types of (non)lethal violence, including completed and attempted homicides, are displayed in the following figure (Fig. 5.2):

Although the distribution pattern of the different victim-offender relationships within the violence-type variable differs slightly - most noticeably in favor of private in case of completed and in favor of public in case of attempted homicides (Fig. 5.1) - clearly bar violence and thievery violence are not very frequent types of violence (Figs. 5.1 and 5.2). Neither are (lethal) violent incidents due to separation/ divorce. Now, recalling the violent Balkan images and stereotypes (Sect. 3.1), this finding makes one wonder about their empirical justification. One would expect at least bar violence to occur much more frequently. Yet, this is not the case. Neither is it the case with regard to thievery (lethal) violence due to burglary, robbery, or theft. However, cautiousness is needed when it comes to such assessments, since incidents lacking phenomenological detail might have been classified as either other private or other public violence, which makes up a total of $62.9 \%$ of all cases. 
other private violence $37.0(\mathrm{~N} 726)$

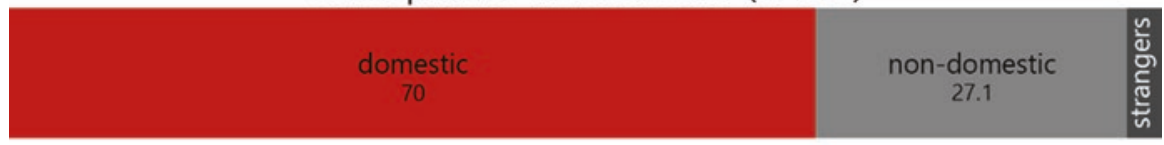

other public violence 25.7 ( $N$ 505)

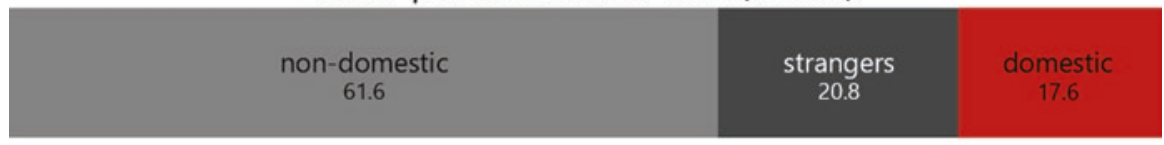

"bar" violence 7.6 ( $N$ 149)

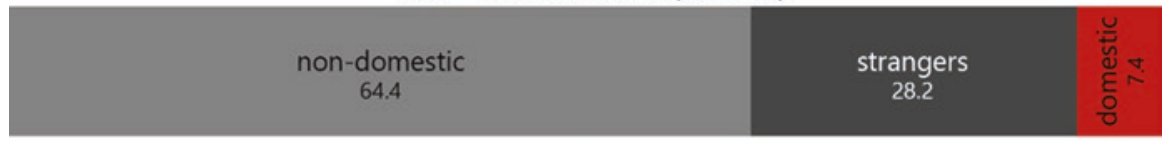

thievery violence 7.4 ( $N$ 145)

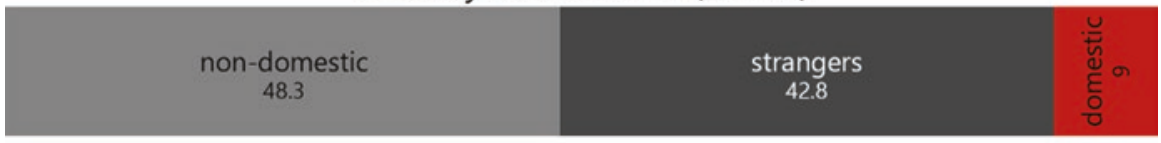

separation violence 7.3 ( $N$ 143)

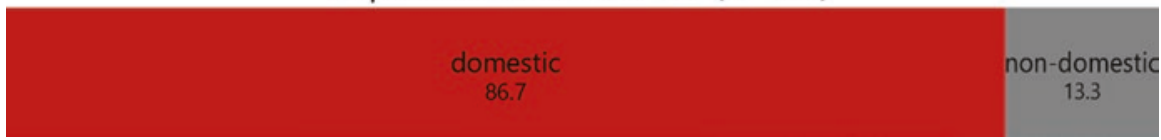

Fig. 5.2 Five most frequent types of (lethal) violence with victim-offender relationship (counting unit: case; $\mathrm{N}$ 1964; $1.7 \%$ missing data; in percentages)

Disregarding these two more general types of violence (N 1255) and focusing only on the phenomenologically much more specific types, the above/below shown distribution appears (Fig. 5.3).

It is almost impossible to assess to what extent such phenomenological distribution pattern of (lethal) violence according to the type of incident captures the realities of (lethal) violence or rather its normative constructions. It is possible that a significant share of bar and thievery violence, as well as any of the other types (both lethal, but even more non-lethal), were not sampled by the BHS. These could, for example, be cases of grave bodily injury (with lethal consequence) or qualified cases of property or sexual offenses (with lethal consequence). Further countryfocused analysis is needed in order to clarify this issue, e.g., by looking into cases of grave bodily injury and property offenses, as well as sexual offenses and other potentially violent crime (with lethal consequences). Nevertheless, even after such in-depth analyses, the question of non-lethal violence (attempted homicides) and its diffusion among non-homicidal offenses would remain unresolved. This conceptual and methodological challenge in essence presents another strong argument in favor of adopting a broader approach toward (lethal) violence research by including nonlethal violence, instead of focusing strictly on (completed) homicides. Yet, at the same time, this challenge also justifies the frequent exclusion of non-lethal violence in (completed) homicide research. If attempted homicides are excluded, then many 


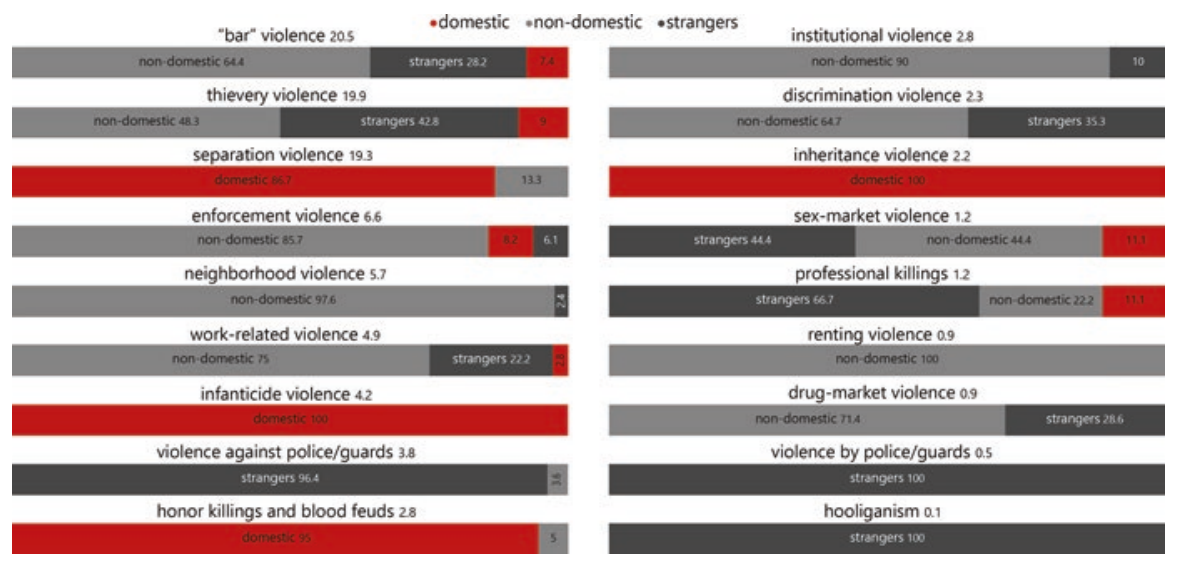

Fig. 5.3 Phenomenologically more specific types of (lethal) violence with victim-offender relationships (counting unit: case; $\mathrm{N}_{\text {valid }} 733 ; 1.7 \%$ missing data; in percentages)

of the above concerns become obsolete. In that sense, and from a practical and pragmatic point, the exclusion of attempted homicides and other non-lethal violence clearly makes sense and is unquestionably justified. But is it really the ideal, or at least the optimal solution for the matter at hand?

\subsection{4 (Lethal) Violence Between Strangers}

Homicide is mainly a convenience crime and a crime of proximity, where the offenders and the victims in most cases know each other (very) well: their interrelationships (and prior interpersonal conflicts) mainly explain the level of (lethal) physical violence, as incidents are overloaded with affect and emotion, whereas crime-related (lethal) violence between strangers is largely instrumental (Mucchielli, 2012, p. 310). Still, what about (lethal) stranger violence that is not crime related or crime-related (lethal) violence between non-strangers? Under the presumption that crime-related violence is instrumental, therefore presumably premeditated, should the victim-offender relationship even matter?

Due to the relatively small share of (lethal) thievery violence in the BHS sample ( $7.4 \%$ or 147 cases) on the one side, and the rather large share of non-stranger relationships within this type (57.2\% or 83 cases), analyzing thievery violence among strangers (62 cases) seems unreasonable. Particularly in light of the cases stemming from six different countries and a prolonged period of time. However, it is sensible to take a closer look at the overall stranger violence in the BHS case sample and present its distribution by type of violence (Fig. 5.4). This should enable us to detect what types of (lethal) violence occur most frequently among strangers and how this differs when compared to non-stranger violence.

Although stranger violence most frequently occurs as other public violence, this type, as already mentioned, also displays a rather large share of non-stranger violence. Thievery violence seems to be a typical form of stranger violence; however, even within 


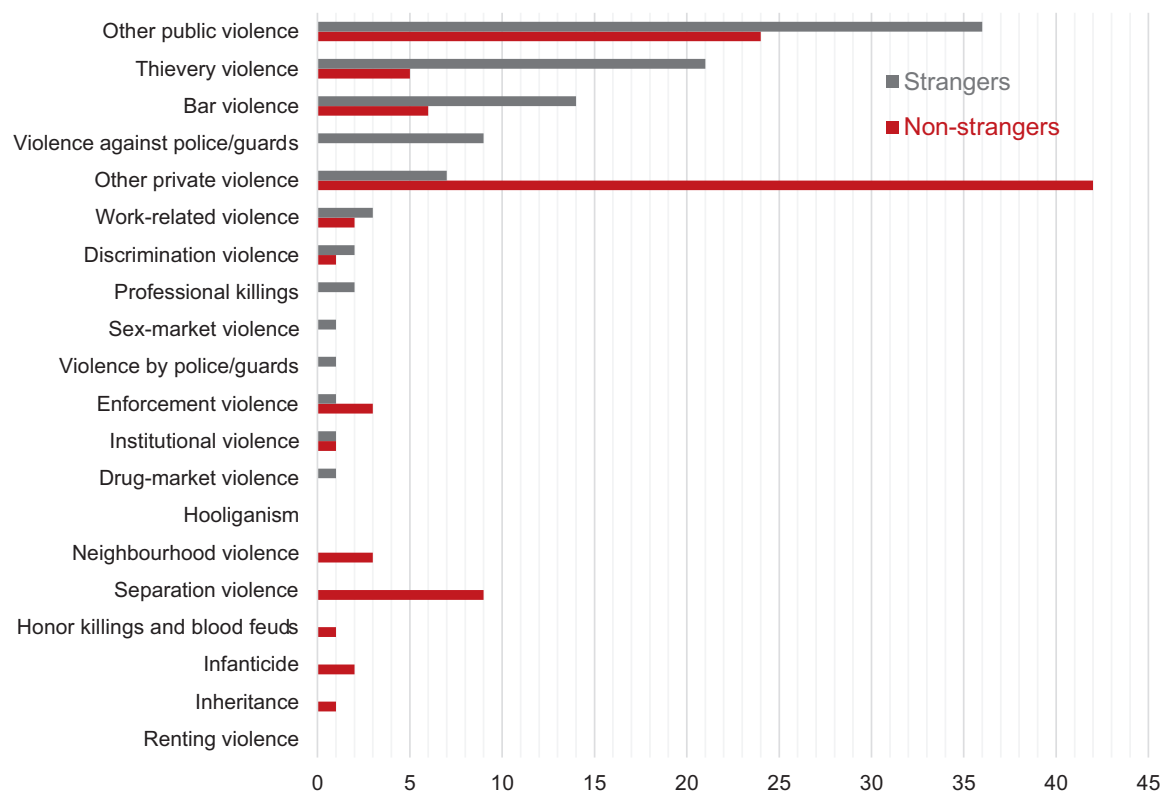

Fig. 5.4 Distribution of stranger and non-stranger victim-offender relationships by types of (lethal) violence (counting unit: case; N 1964; $1.7 \%$ missing data; in percentages)

this type, the share of non-stranger relationships between the victim and the offender is rather high. The same applies to bar violence, with an even higher share of non-stranger relationships (Fig. 5.4). Violence against or by police/guards, professional killings, as well as sex- and drug-market violence are typical forms of stranger violence. Due to classifying the cases based on the incident's situational and contextual characteristics, and in case of limited available details, the need to rely on the "privateness" or "publicness" in terms of space, we also found a significant share of stranger relationships in the other private violence category. This indicates that the (lethal) violent incident, although one between strangers, occurred in a private (non-public) setting.

In the BHS sample, we found that in only $15 \%$ of all cases (lethal), violence occurs among total strangers, whereas the majority of incidents in all countries except for Hungary involves non-domestics (friends/acquaintances). The share of (lethal) violence between domestics (including intimate partners, children, parents, siblings, and relatives) is slightly smaller. In that sense, the findings show that (lethal) violence is indeed a crime of proximity, and that in $85 \%$ of BHS cases, the offenders and the victims know each other (very) well (Table 5.2).

Focusing on Hungary and the higher share of domestic victim-offender relationships, this is likely to be connected to the higher share of female offenders in the Hungary sample (Table 5.3). Female violent offenders in the BHS and in terms of type of violence are more frequently found to have committed other private violence compared to males who most frequently committed other public violence. Likewise, female BHS offenders more frequently commit separation/divorce violence than male offenders, which then relates to the higher share of domestics in the 
Table 5.2 BHS cases by country and victim-offender relationship (counting unit: case; N 1966; $1.6 \%$ missing data; in percentages)

\begin{tabular}{lccccccc}
\hline $\begin{array}{l}\text { Victim-offender } \\
\text { relationship }\end{array}$ & BHS & HR & HU & XK & MK & RO & SI \\
\hline Strangers & 15.0 & 17.6 & 15.3 & 20.0 & 12.5 & 12.2 & 13.5 \\
Non-domestics & 44.3 & 48.0 & 32.3 & 47.7 & 50.0 & 52.8 & 43.6 \\
Domestics & 40.7 & 34.4 & 52.3 & 32.3 & 37.5 & 35.0 & 42.9 \\
\hline Cases & 1966 & 517 & 606 & 65 & 88 & 557 & 133 \\
\hline
\end{tabular}

Legend: $H R$ Croatia, $H U$ Hungary, $X K$ Kosovo, $M K$ North Macedonia, $R O$ Romania, $S I$ Slovenia

Table 5.3 BHS (lethal) violence offenders by gender and country (counting unit: offender) in light of population statistics (gender)

\begin{tabular}{|c|c|c|c|c|c|c|c|}
\hline & BHS & HR & $\mathrm{HU}$ & $\mathrm{XK}$ & MK & RO & SI \\
\hline$\%$ BHS offenders & 100 & 25 & 32 & 4 & 5 & 29 & 6 \\
\hline$\%$ BHS country females & 11 & 12 & 17 & 0 & 5 & 7 & 10 \\
\hline$\%$ Population females $^{\mathrm{a}}$ & 51.2 & 51.8 & 52.3 & - & 49.9 & 51.1 & 51 \\
\hline $\mathrm{N}_{\text {valid }} ; \%$ m.d. & $2295 ; 1$ & $562 ; 0.2$ & $729 ; 0$ & $80 ; 22$ & $107 ; 0$ & $671 ; 0.1$ & $146 ; 0$ \\
\hline
\end{tabular}

Legend: $H R$ Croatia, $H U$ Hungary, $X K$ Kosovo, $M K$ North Macedonia, $R O$ Romania, $S I$ Slovenia, $m . d$. missing data

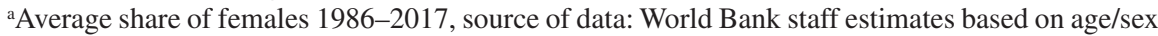
distributions of United Nations Population Division's World Population Prospects: 2019 Revision

Hungary sample, as this sample also displays a comparatively atypically higher share of female offenders.

\subsubsection{Intimate Partner Violence}

Prior research shows that stranger violence is mainly male-on-male violence, whereas intimate partner violence involves a proportionately larger share of women, especially not only as victims but also as perpetrators (Spierenburg, 2012, p. 33). Looking at the total of BHS offenders, we found that stranger violence is predominantly committed by males (96.2\%) and only exceptionally by females (3.8\%). Focusing on offenders' gender and the victim-offender relationships, we found that $18.8 \%$ of male offenders in our sample committed stranger violence compared to only $5.8 \%$ of females. In case of intimate partner violence, $25 \%$ of offenders are females and $75 \%$ males, while out of all offenders, $39.4 \%$ of females committed intimate partner violence compared to only $15.3 \%$ males.

Although a bit tricky, when analyzing the BHS data time-wise, we see that in those years for which the BHS sample has been assessed as most representative (2011-2014, see Fig. 4.2), the share of intimate partner violence clearly dominates over the share of stranger violence (Fig. 5.5). Thus, stranger violence seems to be 


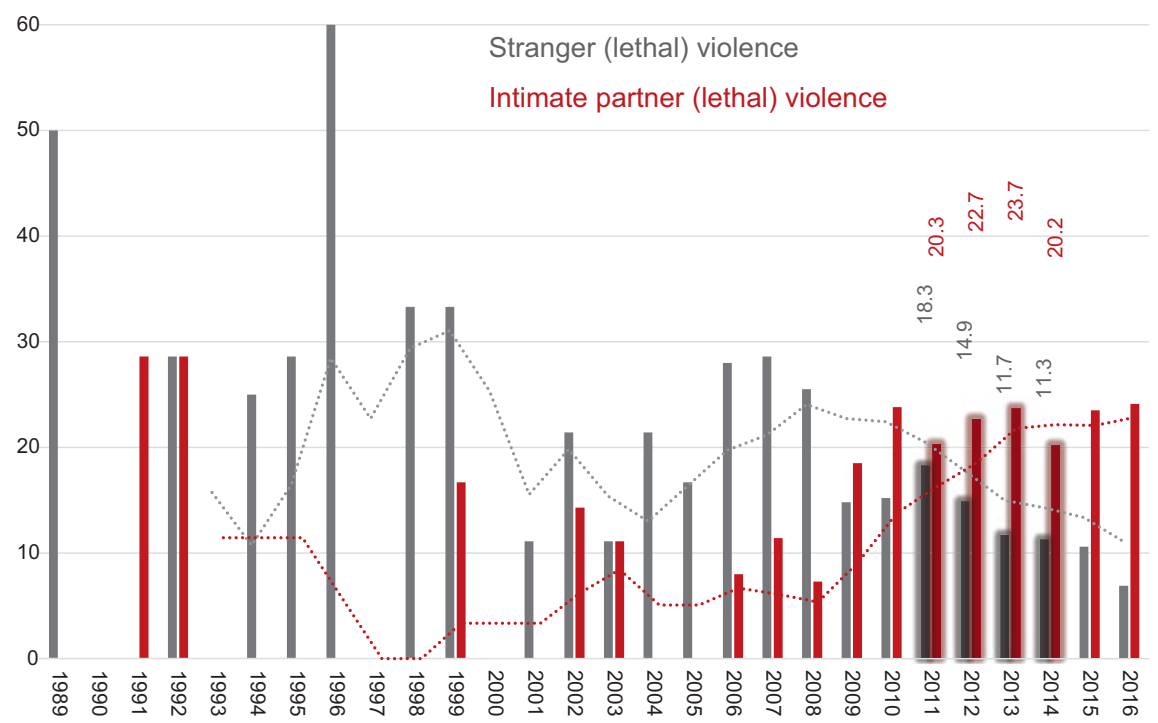

Fig. 5.5 Share of stranger and intimate partner (lethal) violence in BHS sample with 5 year moving average (counting unit: case; $\mathrm{N}_{\text {valid }} 1963 ; 1.7 \%$ missing data)

declining in more recent years, but such data analysis calls for cautiousness, as the aim of the BHS was not to collect data for the purpose of time series analysis, but rather to enable a first cross-sectional snapshot.

\subsection{6 (Attempted) Homicide Followed by Suicide}

Looking more closely at the specific type of (attempted and completed) homicide followed by suicide, it is clear that this is not an insignificant occurrence in the total BHS sample. Even more, if one considers that the typical homicide-suicide constellation in which the offender during or closely-timed to the violent incident commits suicide, is in fact not covered by the BHS sample. At least this is the case when it comes to completed suicides, since in such cases, there will be no prosecution against the (deceased) offender who committed suicide. In $6 \%$ of all (lethal) violence cases, the offender either commits or attempts to commit suicide (3.8\% missings). While the attempted suicides might be time-related to the violent incident, the completed suicides are not. If they were, the incident could not show up in the BHS sample, since the study is based on prosecution/court files and there would be no criminal procedure launched against a deceased offender committing suicide during or closely-timed to the violent incident.

Interestingly, in Hungary (10.3\%), Slovenia (9.6\%), and Croatia (5.8\%), (lethal) violence followed by suicides is a more frequent occurrence than in Romania (2\%), North Macedonia (1\%), or Kosovo $(0 \%)$. Out of all (attempted) homicide-suicide cases, $78.0 \%$ of victim-offender relationships are domestic ones, $17.4 \%$ 
non-domestic, and only $4.5 \%$ between total strangers. Out of these domestic relationships, $69.9 \%$ are those between intimate partners; in $17.5 \%$ of cases, the suicidal offender was the parent of the victim, while in $6.8 \%$ of cases, the suicidal offender was the child of the victim. Out of the non-domestic victim-offender relationships, $73.9 \%$ are between friends and acquaintances. Focusing on the type of violence with regard to (attempted) homicide-suicide, separation/divorce violence instantly stands out with a share of $25 \%$, meaning that one-fourth of (attempted) homicide-suicides in the BHS is separation violence. These results are in line with findings from prior studies showing that uxoricide (the killing of an intimate partner) is the most prevalent type of violence in cases of homicide-suicide (Liem \& Oberwittler, 2012, p. 200). Similarly, our findings confirm that filicide (the killing of a child) is the second most common type of homicide-suicide (Liem \& Oberwittler, 2012, p. 201). One could not go so far as to say that (attempted) homicide-suicide in non-domestic (extrafamilial) relationships between friends and acquaintances in the BHS have been found to be very rare (17.4\%), but they do constitute less than one-fifth of such cases.

The suicidal offenders are predominantly males (82.7\%), when looking only at the offender-suicide variable. However, when looking at the overall distribution of offenders by gender (males $88.7 \%$ vs. females $11.3 \%$ ), it becomes clear that male offenders are in fact less frequently suicidal than expected. Female offenders appear to be more suicidal $(17.3 \%)$ in view of their general share in the total offender sample. This slightly higher proportion of females among the suicidal offenders cannot be explained by infanticides, since this type of violence appeared only in two cases followed by offenders' attempted suicides. This finding on extremely rare suicides when mothers commit infanticides is also in line with findings from previous studies (Liem \& Oberwittler, 2012, p. 201).

Interestingly, homicide-suicide occurs more frequently in the BHS sample in case of completed $(64.7 \%)$ than in the case of attempted $(35.3 \%)$ homicides. Although the homicide-suicide findings originate from the offender database, the 43/57 ratio of completed vs. attempted homicides in this database corresponds quite well to the 42/58 ratio in the case database. Therefore, an approximately 70/30 ratio in favor of completed homicides in case of homicide-suicides confirms that lethal violence occurs more frequently in this type of violence. This might also indicate that homicide-suicides are indeed a distinct type of violence, as has been suggested by previous research (Liem \& Oberwittler, 2012, p. 211).

Finally, looking at the modus operandi the suicidal offender applied, the BHS did not collect data about the suicide's modus operandi, but on the (lethal) incident itself and its primary victim. Here, we see that in most (attempted) homicide-suicide cases, the offenders applied stabbing (46.3\%) and shooting (17.1\%). Although these are also the most frequent methods applied by non-suicidal offenders $(39.9 \%$ stabbing and $12.9 \%$ shooting), it seems that shooting particularly is a bit more emphasized when it comes to homicide-suicide. The role of firearms in homicide-suicide is intriguing, particularly in case of the Balkan region, where rather recent armed conflicts took place and the incidence of illegal firearm possession seems quite high. Results from prior research suggest that the availability of firearms might be one 
causal factor in the genesis of homicide-suicide, while firearms have also been found to be one of the main distinguishing factors between homicide-suicides and homicides only (Liem \& Oberwittler, 2012, p. 212). Further research into homicidesuicides in the Balkans would be needed in order to investigate the full scope of this phenomenon, especially because the BHS did not even capture those cases where the offender committed suicide within the context of the violent incident itself.

\subsubsection{Firearms and (Lethal) Violence}

From the standpoint of the violent Balkan images and stereotypes (Sect. 3.1), the relevance of firearms in connection to (lethal) violence is practically self-evident. It seems plausible to assume that investigating (lethal) violence in the Balkans requires insights into the availability of small firearms and light weapons, especially in view of the tremendous influx of armaments during the "Balkan wars" of the 1990s and given that a large amount of weaponry continues to exist in the region (Grillot, 2010, p. 147). It is said that "the impact of years of civil wars in the Western Balkan region can still be felt to this day, with up to six million small arms still in circulation" (cit. German Federal Foreign Office, 2020). Notwithstanding that illegal firearms possession is a criminal offense in itself throughout all BHS countries and thus poses a challenge for national and regional security, in the context of (lethal) violence, it is necessary to check the assumption that a higher (illegal) firearms availability leads to more (lethal) violence.

At least the BHS findings do not confirm such an assumption, as merely $12.7 \%$ of all offenders in our sample used firearms, in contrast to $21.0 \%$ who used no weapon at all, or in even sharper contrast to those $62.2 \%$ of offenders who used cold weapons. Distinguishing between licensed and unlicensed (legal vs. illegal) firearms, we find that out of all offenders who used a firearm, 58\% of them used an illegally possessed one and $20 \%$ a licensed one, and for $22 \%$ of offenders, the relevant data on firearm license is missing. Clearly, in case a firearm is used for committing an (attempted) homicide, the offenders in the majority of cases used a non-licensed/nonregistered one. This seems plausible considering that most of (lethal) violence incidents in the BHS were committed premeditatedly, not affectively, so that one would expect the offender to use a non-registered firearm which cannot be traced back to him/her.

Although, as stressed earlier, the BHS has not been designed for trend analyses through time, it is however worth mentioning (and thus quite indicative) that there is a noticeable decline in the share of offenders who used firearms during the 1990s and 2000s compared to the most representative time period (2010-2014). Looking at country specifics, we also see a striking difference in the share of offenders using firearms in Macedonia (38.3\%), Kosovo (33.0\%), Croatia (26.1\%), and Slovenia (24.7\%), as compared to Hungary (4.1\%) and Romania (0.9\%). Both these findings taken together and combined with the $12.7 \%$ of offenders using firearms in the total BHS sample, indicate that there might be a link between past armed conflicts, the 
availability of (illegal) firearms and their more frequent usage in violent incidents. Further analyses are obviously needed, but for the time being, it seems that in the 2010s and compared to the previous two decades, there is a decline in the incidence of firearms usage in interpersonal (lethal) violence.

One might perhaps expect, that in the case an offender used a firearm, the outcome of the violent incident is more likely to be lethal, but first descriptive analyses do not confirm such an assumption. On the contrary, in those instances when offenders used firearms, the outcome of the incident was lethal (e.g., the homicide completed) in only $48.6 \%$ of cases, whereas in cases the offender used no weapon, the outcome was lethal in $63.3 \%$ of cases. Since the completed/attempted homicide ratio in the total sample is 43/57, the inverted ratio of completed and attempted homicides in case of firearms usage does not confirm a higher lethality due to firearms usage. Now, obviously the firearms data is quite country specific and appears to be time sensitive, as well as dependent on the type of violence and affective or premeditated perpetration of the incident. Data shows that in $42.5 \%$ of incidents, the offenders acted affectively, compared to $57.5 \%$ of premeditated incidents. In the case of firearms usage, the ratio between affective and premeditated was 38/62 compared to 25/75 when no weapons were used, or 49/51 in case cold weapons were used. The lethality of the incident outcome is unquestionably determined by a combination of multiple factors, among which the usage of (illegal) firearms seems to play a less significant role, at least compared to cold weapons.

\subsubsection{Alcohol and (Lethal) Violence}

Prior research shows that alcohol consumption has an effect on homicide rates in Eastern Europe and that this effect varies with drinking pattern (Bye, 2008). Thus, alcohol-related homicides are more likely the result of acute arguments, more likely to be affective, and less likely to involve strangers, compared to homicides that did not involve alcohol (Spierenburg, 2012, p. 163). In view of these findings, the first issue to address relates to the potential impact of alcohol on (lethal) violence in terms of completed vs. attempted homicides. Out of all the offenders, $43.6 \%$ committed a homicide, with $56.4 \%$ attempting a homicide. Nearly $40.7 \%$ of offenders who were under the influence of alcohol tempore criminis completed the homicide compared to $59.3 \%$ of them who failed in their attempt to do so, while $44.2 \%$ of the non-intoxicated offenders completed the homicides compared to $55.8 \%$ who did not. There does not seem to be a markable difference between completed and attempted homicides with regard to the offenders' alcohol intoxication in the BHS.

When looking at the issue of affective (lethal) violence, out of those offenders under the influence of alcohol, $52.9 \%$ acted affectively compared to only $32.6 \%$ of affective offenders among the non-intoxicated offender group. In cases of intoxicated offenders, the victim-offender relationship is slightly less frequently one between strangers $(15.1 \%)$ than in case of non-intoxicated offenders $(18 \%)$. Both BHS results seem to confirm findings from previous research. Thus, alcohol seems 


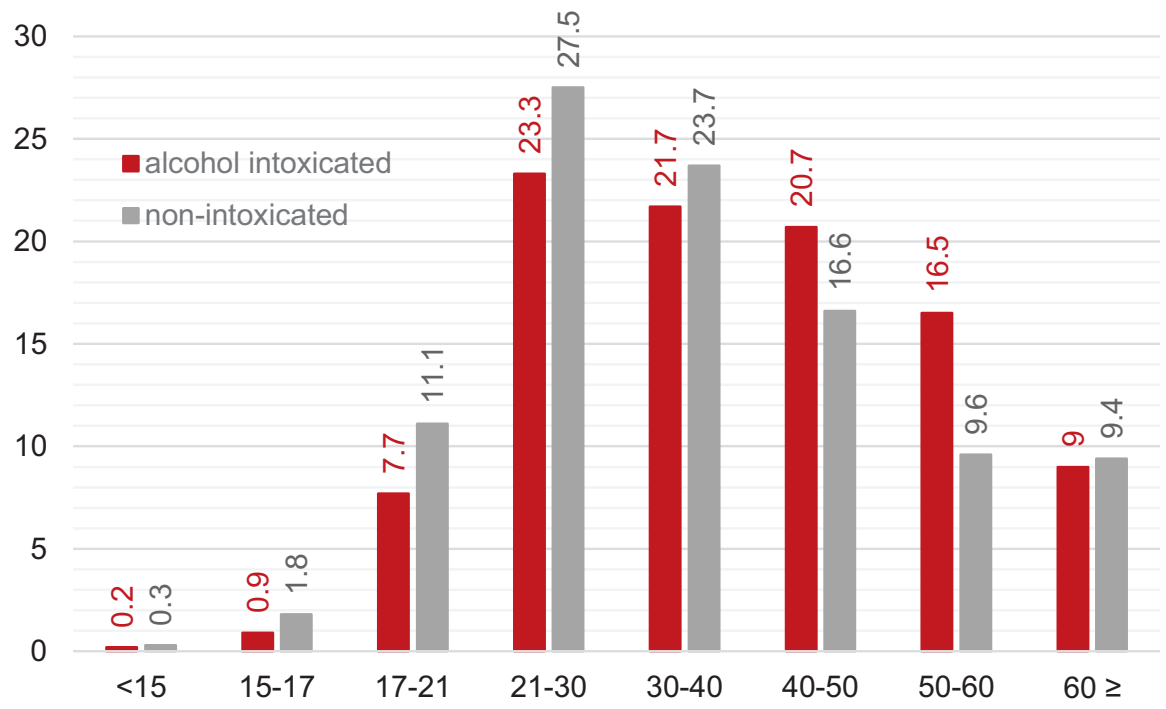

Fig. 5.6 BHS (lethal) violence offenders by age and alcohol intoxication tempore criminis (counting unit: offender; $\mathrm{N}_{\text {valid }} 2097 ; 9.7 \%$ missing data; in percentages)

to have played a different role in various types of violence by victim-offender relationship: intoxicated offenders slightly more frequently engaged in violence with their intimate partners (intoxicated 19.6\%, non-intoxicated 17\%), siblings (intoxicated $2.9 \%$, non-intoxicated $1.2 \%$ ), friends/acquaintances (intoxicated $41.5 \%$, nonintoxicated $35.7 \%$ ), and relatives (intoxicated $7.3 \%$, non-intoxicated $4.8 \%$ ), and slightly less frequently with their children (intoxicated $2.4 \%$, non-intoxicated $5.9 \%$ ), parents (intoxicated 3.3\%, non-intoxicated 6.6\%), neighbors (intoxicated $3 \%$, non-intoxicated 3.8\%), and co-workers (intoxicated 2.9\%, nonintoxicated $4.7 \%$ ).

With regard to motive and alcohol-related (lethal) violence, there is no difference in the distribution pattern. Intoxicated as well as non-intoxicated offenders most frequently seem to be motivated by revenge (intoxicated 28\%, non-intoxicated $27.3 \%$ ) and greed (intoxicated $10.4 \%$, non-intoxicated $18.1 \%$ ). The most striking difference appears with respect to the category of unclear motive (intoxicated $49.3 \%$, non-intoxicated $40.5 \%$ ), which could mean that in case of intoxicated offenders, their actions were less rational and therefore more difficult to classify.

As Fig. 5.6 illustrates, alcohol-related (lethal) violence is unequally distributed among the different offender age groups, although it has a similar distribution within the overall sample in which $45.7 \%$ of offenders were intoxicated tempore criminis, while $54.3 \%$ were not. It seems that alcohol intoxication in the BHS plays a much more important role when it comes to lethal violence committed by offenders aged 40-50 and 50-60 than those younger than 40. This might make sense in light of the rather low share of bar violence within the BHS sample, for which commonly young males under the influence of alcohol are deemed responsible. 


\subsubsection{The Organized Crime Violence Nexus}

It has frequently been stressed that there is a strong nexus between organized crime and (lethal) violence. Organized crime as such can be a significant source of lethal violence - it is assessed that from the start of the twenty-first century, organized crime has caused approximately the same number of killings as all armed conflicts across the world combined (UNODC, 2019, p. 12). It has thus been highlighted that organized crime is a particularly worrisome crime phenomenon in the Balkans and more broadly throughout Southeastern Europe: "The threat of organized crime is growing ever more present and powerful in the South Eastern Europe region" (cit. UNODC, 2020). And although there are plenty of evident cases of lethal violence connected to the criminal underworld throughout the region (e.g., Jovanović et al., 2020), in the whole BHS sample, only six offenders were linked to such organized crime-related violence - four of them from Hungary and two of them from Slovenia. By broadening the conception of organized crime-related violence and looking at offenders of "criminal transaction related violence," 38 such offenders were identified (1.6\% of all offenders), but only 1 offender when it comes to "gang-related violence."

Out of numerous potential explanations for this rather low share of organized crime-related or illegal market-related violence, two shall be briefly addressed. First, due to methodological issues, such cases were not sampled in a representative manner. This could be a consequence of different normative frameworks or lack of prosecution of such cases (e.g., unknown offenders). It could also be that such cases are in fact in the sample, but were not identified due to deficient data collection efforts during the field work and case analysis. Although possible, this does not seem very likely. Second, there are relatively few cases of organized crime-related violence in the sampled countries, or the dark figure of such cases is very high. Due to domestic and foreign media attention on the topic of organized crime in the Balkans, such (potentially rare) incidents of (lethal) violence get picked up and reported upon extensively. This might create the impression that organized crimerelated violence occurs frequently throughout the region, although compared to non-organized crime-related (lethal) violence, the incidence of such cases is extremely low (at least in the sampled countries). Most likely both explanations combined have had an influence on the BHS findings. Further research would clearly be needed in order to confirm these assumptions, but for now and based on the BHS, it seems that higher homicide rates throughout the region cannot simply be attributed to higher levels of organized crime and violence committed by or in the criminal underworld - at least not based on prosecution and court files.

\subsubsection{0 (Lethal) Violence and Cruelty}

The last topic to be discussed with regard to incident characteristics deals with (lethal) violence and particular cruelty. Particular cruelty was defined as an excessive amount of aggression toward the victim that can be recognized by looking at the modus operandi of the offender (e.g., killing the victim by burning it alive or 
mutilating the body of the victim). The difference in gender, age, or physical ability between the victim and the offender was explicitly disregarded, and it was made clear that with the "cruelty variable," we were not aiming to identify "normal" qualified or more severe cases, but rather looking for the "extraordinary" among the most severe cases of (lethal) violence.

In the BHS, 30 cases of particularly cruel violence were identified, all of them lethal and amounting for a total of 38 offenders. More than two-thirds of these cruel offenders acted premeditated; the majority of them were male ( $86.8 \%$ compared to $88.5 \%$ in case of non-cruel offenders), half of them were under the influence of alcohol tempore criminis, and only four were under the influence of drugs. In most instances, the offender's main motive remained unclear (20), whereas the remaining offenders acted out of revenge (11), greed (6), or (self)defense (1). The victimoffender relationship displays a different distribution pattern, with a bigger share of violence against one's children (10.5\%) and intimate partners (23.7\%) and a lower share of stranger violence (7.9\%). Most of the "cruel offenders" were typed as having committed general private violence (24), followed by infanticide (4), separation violence (3), thievery violence (3), bar violence (2), renting violence (1), and enforcement violence (1). Clearly, particularly cruel violence is not related to public violence, at least not in the BHS sample.

Out of all the cruel incidents, the majority of cases (29) was a completed homicide, whereby 4 victims survived and 28 were killed. Cruel violence was suffered by 32 victims ( 28 cases with 1 victim, 2 cases with 2 victims). Not surprisingly, in almost all cases in which the offender acted particularly cruel, a psychiatric expertise was ordered (92.1\% vs $67.5 \%$ non-cruel offenders). Nevertheless, "cruel offenders" were not more frequently found to be insane or of diminished criminal responsibility, both significant and insignificant ( $80 \%$ of cruel offenders were found fully criminal responsible vs $67.3 \%$ of non-cruel offenders). Finally, when focusing on the victims of particularly cruel violence (32), the majority of them is female (62.5\%), whereby this share of female violence victims is more than twice as big as in case of non-cruel violence $(28.5 \%)$, where the majority of victims is male (71.5\%). This finding makes particular sense in view of the large share of domestic violence and the specific types of violence found among the cruel cases, where females commonly are far more exposed to victimization than males, as will be demonstrated in Sect. 5.3.

\subsection{Offender Characteristics}

After just having described the main features of (lethal) violence incidents, we now turn to the characteristics of the violent offenders. After briefly discussing the scope and potential impact of the missing data problem in the BHS offender database, key issues in merging the different databases will be addressed. This will be followed by a general overview of the findings on offender characteristics. In a next step, offender characteristics will be analyzed with respect to particular types of (lethal) 
violence, as well as potential risk factors such as alcohol and prior convictions for (violent) offenses. This section will provide a general overview on violent offender characteristics and potential risk factors by sample countries, as much as it will give first insight into specific offender types/groups (e.g., male violence).

\subsubsection{Missing Offender Data}

The BHS's offender variables (counting unit: offender; N 2321; Table 4.3) display a broader scope of the missing data problem as compared to the case variables (see Appendix). In case of the variables on BHS violence typology, victim-offender relationship, motive as well as sexual or particularly cruel modus operandi, this is due to having based these variables on the case descriptions (less cases than offenders). In order to analyze these (and other case-based variables) with a focus on the violent offenders, the relevant variables were included in the offender database and in case of multiple offenders duplicated accordingly. The same applies for the victim database. The methodological pitfalls of such a procedure are quite obvious. Nevertheless, this procedure appeared to be the most meaningful solution. Just as the application of the principle offence rule may somewhat distort the findings, so does this principle case rule.

More than half of the offender variables display a share of less than 5\% of missing data. The most problematic variables with a share of more than $10 \%$ of missing data relate to the following: firearm license (30.8\%), ethnicity $(19.6 \%)$, length of prison sentence $(18.7 \%$ partly due to not all offenders having been convicted or sentenced to a prison sentence), long-term prison sentence (17.9\% partly due to not all offenders having been convicted or sentenced to a prison sentence), length of detention $(24.4 \%)$, addiction $(15.3 \%)$, legal qualifications of the offense (first instance $15.2 \%$, final instance $14.9 \%$, police $14.3 \%$, prosecution $11.2 \%$ ), no children and number of children (14\%), drug intoxication (10.7\%), and mitigated sentencing (10.3\%) (see Appendix). Although far from ideal, when it comes to missing data and in view of the type of data source, the majority of variables seems suitable for analysis, while some of them need to be consumed with caution. Throughout the following paragraphs, particular cautiousness due to missing data will be indicated, wherever relevant.

\subsubsection{Merging Databases with Different Counting Units}

So far, throughout the analysis in this chapter, only some of the variables have been based on findings from two different databases with different counting units (case and offender as counting units). This requires a merging of the relevant databases and, as a consequence, results in either dropping or duplicating certain case data. Now, when analyzing offender characteristics in light of victim and case data, this 
merging of databases with dropping or duplicating relevant data becomes even more challenging and complex. Basically, a case of (non)lethal violence in the BHS commonly has one offender and one victim (81\%). However, in some instances, a case has more than one offender $(11 \%)$ or more than one victim (10\%). Exceptionally, a case involves both several offenders and several victims (2\%). In all these cases with multiple offenders and/or several victims, the merging of the three different databases (with three different counting units) requires a dropping or duplication of data. Now, when merging case data with offender or victim data (as has been done for Sect. 5.1), the duplication of relevant case data is meaningful and justified, since both offender and victim data unquestionably relate to the same case.

For example, two offenders killed three victims in a bar. When merging case data with the offender data, e.g., to find out the time of day the incident took place and whether the offenders were under the influence of alcohol or have prior convictions, then the relevant case data (time of day) becomes a new variable in the offender database, where it is duplicated for all three offenders. The same applies for merging case and victim data. In essence, such merging of data is nothing more than connecting relevant case data to the appropriate offender and/or victim in order to enable data analysis. The assumption here is that if the same variables would have been included in the questionnaire's section dealing with offender and victim data, then the values would have been the same as in the case section and identical for multiple offenders and victims within the same case. In contrast to this and when it comes to merging offender with victim data, the aforementioned assumption is simply wrong. For example, two offenders kill a man, his wife, and attempt, but fail, to kill their two children in a case of a burglary gone wrong. Simply duplicating offender data into the victim database would imply the fictional construction of two new offenders for each of the four victims. Besides "inventing" six realistically nonexistent offenders and "inventing" four realistically non-existent victims in the victim or offender database (depending which one you look at), the question arises which offender and which victim should be duplicated?

Long story short - the duplication of offender and victim data in case of several offenders and/or several victims does not appear meaningful for analyzing the BHS data. Moreover, such procedure would considerably distort the findings. Therefore, the most meaningful and viable solution for the BHS is to disregard (drop) those cases that involve multiple offenders and/or victims entirely from offender-victimcase analysis. This is clearly not an ideal solution, but in light of the consequential loss of "only" $19 \%$ of all cases, respectively $23 \%$ of all offenders and respectively $22 \%$ of all victims, appears to be an optimal solution, and one that does not distorts the findings - especially if one keeps in mind that the following findings from combined offender-victim-case analysis are limited to (non)lethal violent incidents involving only one offender and one victim. 


\subsubsection{General Offender Characteristics}

In addition to some of the more general offender characteristics that have already been discussed in relation to the incident characteristics (Sect. 5.1), such as alcohol intoxication or modus operandi, the following paragraphs display general findings on violent offenders' gender, age, family status, prior convictions, education and income, nationality, ethnicity, etc. Naturally, the findings need to be interpreted in light of the particular country situation, as well as the relevant (violent and nonviolent) crime context. Yet, this is a task that would significantly broaden the scope and focus of this book. This will be the next big step in analyzing the BHS data in full detail and in the relevant country and crime context. The general offender characteristics will thus be displayed for the total BHS sample, as well as specific to the countries (Table 5.3).

Looking at all BHS offenders in terms of gender (Table 5.3) and age (Fig. 5.7), we see that the vast majority of violent offenders are male and only exceptionally female, whereby the group of female offenders displays an older age curve than the group of male offenders (Fig. 5.7). A similar gender distribution can be found in the different countries, whereby the share of female violent offenders is exceptionally high in Hungary, followed by Croatia, Slovenia, Romania, and North Macedonia (Table 5.3). This exceptionally high share of female offenders in the Hungarian BHS sample (17\%) is clearly not a consequence of a higher share of females in the Hungarian population - the gender ratio in the BHS countries is rather constant and is approximately $1: 1$. The Kosovo BHS sample contains a total of 81 violent offenders, but not a single female offender, and it also displays a large share of missing data $(22 \%)$. Obviously, the overall high share of female offenders in the total BHS sample is under the influence of the high share of female offenders in the Hungarian sample. Nevertheless, (non)lethal violence can clearly be characterized as a typical male type of crime in the BHS sample.

Analyzing the age curve of the offenders in the different BHS countries (Fig. 5.7, Table 5.4), for male offenders, we find a clear peak in the age group 21-30 (except for Hungary with a peak at 30-40), whereas the female age curve peaks at 30-40 or
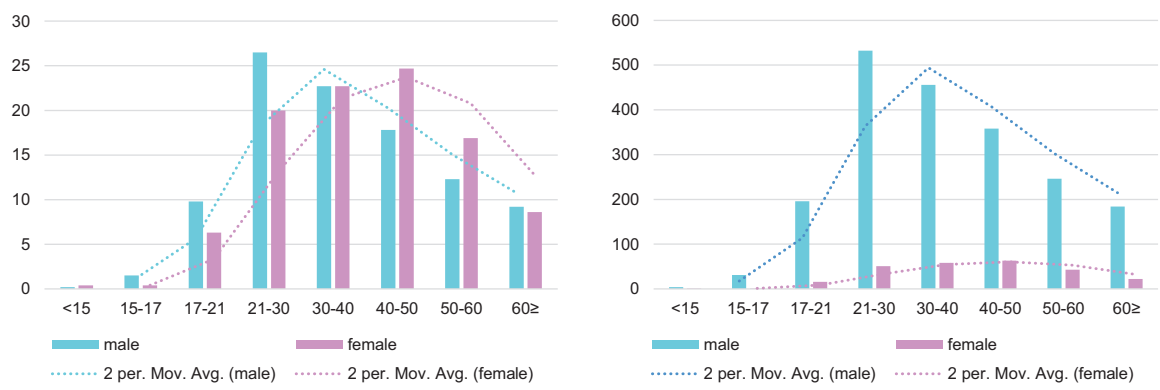

Fig. 5.7 BHS (lethal) violence offenders by gender and age groups in offender numbers (left) and as shares within gender (right) (counting unit: offenders; $\mathrm{N}_{\text {valid }} 2262 ; 2.5 \%$ missing data) 
Table 5.4 BHS (lethal) violence offenders by age groups, gender, and country (counting unit: offender)

\begin{tabular}{|c|c|c|c|c|c|c|c|}
\hline $\begin{array}{l}\text { Age } \\
\text { groups \% }\end{array}$ & $\begin{array}{c}\text { BHS } \\
\text { 치우 }\end{array}$ & $\begin{array}{l}\mathrm{HR} \\
\text { गे|우 } \\
\end{array}$ & 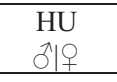 & $\begin{array}{l}\mathrm{XK} \\
\text { गै।lo } \\
\end{array}$ & $\begin{array}{l}\text { MK } \\
\text { 히우 }\end{array}$ & $\begin{array}{l}\text { RO } \\
\text { 시오 }\end{array}$ & $\begin{array}{l}\text { SI } \\
\text { SIlo }\end{array}$ \\
\hline$<15$ & $0.2 \mid 0.4$ & $0 \mid 0$ & $0 \mid 1$ & $0 \mid 0$ & $0 \mid 0$ & $1 \mid 0$ & $0 \mid 0$ \\
\hline $15-17$ & $2 \mid 0.4$ & $0.8 \mid 0$ & $2 \mid 1$ & $0 \mid 0$ & $0 \mid 0$ & $3 \mid 0$ & $0 \mid 0$ \\
\hline $17-21$ & $10 \mid 6$ & $6 \mid 5$ & $11 \mid 7$ & $16 \mid 0$ & $11 \mid 0$ & $12 \mid 2$ & $3 \mid 21$ \\
\hline $21-30$ & $27 \mid 20$ & $25 \mid 20$ & $22 \mid 17$ & $33 \mid 0$ & $33 \mid 40$ & $29 \mid 25$ & $32 \mid 29$ \\
\hline $30-40$ & $23 \mid 23$ & $20 \mid 19$ & $26 \mid 24$ & $16 \mid 0$ & $24 \mid 0$ & $23 \mid 30$ & $21 \mid 14$ \\
\hline $40-50$ & $18 \mid 25$ & $20 \mid 25$ & $18 \mid 27$ & $24 \mid 0$ & $14 \mid 20$ & $15 \mid 23$ & $22 \mid 14$ \\
\hline $50-60$ & $12 \mid 17$ & $15 \mid 20$ & $13 \mid 18$ & $5 \mid 0$ & $9 \mid 20$ & $11 \mid 9$ & $10 \mid 14$ \\
\hline $60 \geq$ & $9 \mid 9$ & $13 \mid 12$ & $9 \mid 6$ & $6 \mid 0$ & $8 \mid 20$ & $7 \mid 11$ & $12 \mid 7$ \\
\hline $\mathrm{N}_{\text {valid; }} \%$ m.d. & $2262 ; 2.5$ & $549 ; 2.5$ & $714 ; 2.1$ & $80 ; 22$ & $104 ; 2.8$ & $670 ; 0.3$ & $145 ; 0.7$ \\
\hline
\end{tabular}

Legend: $H R$ Croatia, $H U$ Hungary, $X K$ Kosovo, $M K$ North Macedonia, $R O$ Romania, $S I$ Slovenia, $m . d$. missing data; $\sigma^{\top}$ male, 우 female

40-50 (except for N. Macedonia and Slovenia with a peak at 21-302). The male offenders are clearly younger than the female ones and it will be exciting to see whether and how this is related to the different types of (lethal) violence the offenders engage in.

There is no question that gender and age are strong predictors of criminal behavior, including violent one, just as they are, generally speaking, strong predictors of any kind of human behavior - not only criminal one. Similarly, relationship status, parenthood, education, employment and income, or prior convictions and imprisonment are commonly investigated in order to detect potential criminogenic risk factors or possible protective circumstances. ${ }^{3}$ For a full interpretation of the BHS findings with regard to all these factors, one would need to analyze other groups of offenders (e.g., non-violent offenders) as well as general population characteristics (in each of the sampled countries). Therefore, these factors will be presented and analyzed as descriptive findings, without assessing their potential impact, which will need to be done in future country-specific analysis.

\footnotetext{
${ }^{2}$ Note: This difference in the peak of the female age curve for N. Macedonia and Slovenia is most likely due to the very small numbers of female offenders in combination with a significantly smaller sample size compared to the remaining countries.

${ }^{3}$ These are only those factors captured by the BHS due to their availability in the data sources (case files). Criminological research commonly also focuses on other factors that might influence (violent) criminal behavior (e.g., living conditions and neighborhood characteristics, childhood abuse, parental alcohol, and/or drug addiction), but which are not subject to the analysis at hand due to lack of relevant data in the case files.
} 
Table 5.5 BHS (lethal) violence offenders by relationship status, gender, and country (counting unit: offender)

\begin{tabular}{|c|c|c|c|c|c|c|c|}
\hline $\begin{array}{l}\text { Relationship } \\
\text { status \% }\end{array}$ & $\begin{array}{l}\text { BHS } \\
\text { ㅊ|우 }\end{array}$ & $\begin{array}{l}\mathrm{HR} \\
\text { 시우 }\end{array}$ & $\begin{array}{l}\mathrm{HU} \\
\text { 이우 }\end{array}$ & $\begin{array}{l}\mathrm{XK} \\
\text { 치우 } \\
\end{array}$ & $\begin{array}{l}\text { MK } \\
\text { 히우 }\end{array}$ & $\begin{array}{l}\text { RO } \\
\text { गै|우 }\end{array}$ & $\begin{array}{c}\text { SI } \\
\text { 시우 }\end{array}$ \\
\hline Single & $42 \mid 19$ & $41 \mid 22$ & $38 \mid 21$ & $44 \mid 0$ & $39 \mid 0$ & $47 \mid 7$ & $42 \mid 36$ \\
\hline Married & $29 \mid 38$ & $34 \mid 48$ & $18 \mid 33$ & $56 \mid 0$ & $53 \mid 80$ & $29 \mid 34$ & $22 \mid 29$ \\
\hline Cohabitation & $16 \mid 25$ & $9 \mid 14$ & $27 \mid 27$ & $0 \mid 0$ & $1 \mid 20$ & $15 \mid 41$ & $27 \mid 1$ \\
\hline Divorced & $10 \mid 12$ & $11 \mid 9$ & $15 \mid 12$ & $0 \mid 0$ & $5 \mid 0$ & $6 \mid 11$ & $7 \mid 29$ \\
\hline Widowed & $2 \mid 5$ & $4 \mid 3$ & $2 \mid 6$ & $0 \mid 0$ & $1 \mid 0$ & $2 \mid 7$ & $2 \mid 0$ \\
\hline Other & $1 \mid 1$ & $2 \mid 3$ & $1 \mid 1$ & $0 \mid 0$ & $2 \mid 0$ & $1 \mid 0$ & $0 \mid 0$ \\
\hline $\mathrm{N}_{\text {valid; }} \%$ m.d. & $2234 ; 3.7$ & $539 ; 4.3$ & $703 ; 3.6$ & $78 ; 24$ & $106 ; 1$ & $666 ; 1$ & $142 ; 3$ \\
\hline
\end{tabular}

Legend: $H R$ Croatia, $H U$ Hungary, $X K$ Kosovo, $M K$ North Macedonia, $R O$ Romania, $S I$ Slovenia, $m . d$. missing data, $\sigma^{\top 7}$ male, 우 female

Looking at offenders' relationship status, we observe a quite similar share of offenders who are single and those who are in a relationship if not distinguishing between male and female offenders. Most of the offenders who are in a relationship are married and less frequently live in an extra-marital relationship (cohabitation), while the single offenders are most frequently single and less frequently divorced or widowed. However, when analyzing offenders' relationship status and accounting for gender differences, we observe that male offenders are far more frequently single than female offenders, who are usually married or live in a cohabitation (Table 5.5), which is probably connected to the different age curve of male and female offenders (Fig. 5.7). Nevertheless, when combining the categories married and cohabitation, then this broader category is clearly the most frequent relationship status for both male and female offenders in the overall BHS sample, but also in the country samples, except for male offenders in Romania (mainly single) and female offenders in Slovenia (mainly single). The missing data issue is again problematic when it comes to the BHS Kosovo sample (24\%), but quite modest in the rest of the country samples.

In terms of parenthood, most male and female offenders do have children, whereas slightly less offenders do not have any children (Table 5.6). We observe that the share of female offenders with children is far bigger than that of male offenders with children. This is probably again connected to the "older" age curve of female offenders and their more frequent marital and/or cohabitational relationship status. We also observe that this more in-depth biographical information about the offenders' family status displays far more missing data than the prior offender characteristics (Table 5.6). This is to be attributed to the lack of relevant biographical information in the analyzed case files rather than poor data collection efforts in most of the countries - the exception is again the Kosovo sample, where a high share of missing data is a rather constant feature for many of the variables (see Appendix). 
Table 5.6 BHS (lethal) violence offenders by parenthood, gender, and country (counting unit: offender)

\begin{tabular}{|c|c|c|c|c|c|c|c|}
\hline Parenthood \% & $\begin{array}{c}\mathrm{BHS} \\
\text { 히오 }\end{array}$ & $\begin{array}{l}\mathrm{HR} \\
\text { d'I오 }^{2}\end{array}$ & 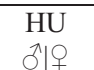 & $\begin{array}{l}\mathrm{XK} \\
0^{\pi} \mid ㅇ ㅗ\end{array}$ & $\begin{array}{l}\text { MK } \\
\text { ॠ|오 }\end{array}$ & $\begin{array}{l}\mathrm{RO} \\
\text { 히오 }^{2}\end{array}$ & $\begin{array}{c}\text { SI } \\
\delta^{\lambda} \mid \text { 保 }\end{array}$ \\
\hline Yes & $54 \mid 73$ & $53 \mid 79$ & $52 \mid 64$ & $51 \mid 0$ & $74 \mid 100$ & $54 \mid 90$ & $56 \mid 67$ \\
\hline No & $46 \mid 27$ & $47 \mid 21$ & $48 \mid 36$ & $49 \mid 0$ & $26 \mid 0$ & $46 \mid 10$ & $44 \mid 33$ \\
\hline $\mathrm{N}_{\text {valid; }} \%$ m.d. & $1965 ; 14$ & $532 ; 6$ & $669 ; 8$ & $72 ; 30$ & $81 ; 24$ & $495 ; 26$ & $146 ; 0$ \\
\hline
\end{tabular}

Legend: $H R$ Croatia, $H U$ Hungary, $X K$ Kosovo, $M K$ North Macedonia, $R O$ Romania, $S I$ Slovenia, $m . d$. missing data, $\sigma^{\top 7}$ male, 우 female

Looking at all BHS offenders' educational background, employment, and income, we find that most offenders have a secondary education (high school), are mainly unemployed, and have a below-average income (Table 5.7). For most variables in the majority of BHS countries (except for Kosovo), the share of missing data is rather modest. Despite country differences, it is safe to conclude that BHS offenders have a mid- and lower-level educational background, with a noticeable share of those with no formal education at all, which applies for both genders. The category of other education includes faculty and $\mathrm{PhD}$-level education, whereas the category of higher education includes an in-between-level education that follows secondary education (high school), but in contrast to a university degree faculty education, it is more practice/work oriented and typically lasts 2-3 years.

Now, the variable capturing the offenders' employment status shows that most offenders are unemployed, at least according to information contained in the analyzed case files. It is however quite common throughout the region and in the private business sector that workers are not officially registered as employees or that goods and services are offered outside the framework of a registered business. Unregistered labor markets and shadow economies throughout the region are clearly an issue to keep in mind (Botrić, 2011, p. 95). Same cautiousness is in place when contextualizing BHS findings on offenders' income, since even in cases when the workers or businesses are registered, there is a quite common practice in most of the countries to report only minimum wages or turnovers. This might very well explain the discrepancy found in the relevant BHS data, where the "no-income" data does not overlap with the "not-employed" data. This shows that some offenders, despite being unemployed, do have an income. This could however also be due to an income based on unemployment or other social grants. In any event, violent offenders in the BHS sample can clearly be characterized as a below-average or no-income group, which again goes for both genders and applies to all the BHS countries.

Criminologically speaking, recidivism is always a fascinating topic, particularly in relation to new criminal behavior and the question whether prior criminal behavior, captured by convictions and/or prison experience, might have played a role in the offender's criminogenesis. Obviously, the fact that an offender has no prior conviction(s) does not mean that he/she has not already committed a criminal 
Table 5.7 BHS (lethal) violence offenders by education, employment, income, gender, and country (counting unit: offender)

\begin{tabular}{|c|c|c|c|c|c|c|c|c|}
\hline & & $\begin{array}{c}\text { BHS } \\
\text { 치우 }\end{array}$ & $\begin{array}{l}\mathrm{HR} \\
\text { 히우 }\end{array}$ & $\begin{array}{l}\mathrm{HU} \\
\text { 히우 }\end{array}$ & $\begin{array}{l}\text { XK } \\
\text { गै|우 }\end{array}$ & $\begin{array}{l}\text { MK } \\
\text { 치우 }\end{array}$ & $\begin{array}{l}\text { RO } \\
\text { 히우 }\end{array}$ & 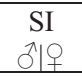 \\
\hline \multirow{6}{*}{ 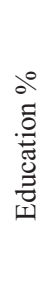 } & Secondary & $45 \mid 45$ & $57 \mid 57$ & $41 \mid 40$ & $24 \mid 0$ & $40 \mid 60$ & $43 \mid 44$ & $44 \mid 29$ \\
\hline & Elementary & $35 \mid 35$ & $34 \mid 25$ & $48 \mid 47$ & $15 \mid 0$ & $44 \mid 0$ & $25 \mid 15$ & $36 \mid 50$ \\
\hline & Higher & $10 \mid 6$ & $2 \mid 5$ & $0.2 \mid 1$ & $58 \mid 0$ & $4 \mid 0$ & $23 \mid 28$ & $4 \mid 0$ \\
\hline & None & $7 \mid 7$ & $2 \mid 5$ & $10 \mid 7$ & $0 \mid 0$ & $10 \mid 20$ & $7 \mid 8$ & $15 \mid 14$ \\
\hline & Other & $3 \mid 7$ & $5 \mid 9$ & $1 \mid 5$ & $3 \mid 0$ & $2 \mid 20$ & $2 \mid 5$ & $1 \mid 7$ \\
\hline & $\mathrm{N}_{\text {valid }} \%$ m.d. & $2108 ; 9$ & $532 ; 6$ & $653 ; 10$ & $71 ; 31$ & $99 ; 8$ & $616 ; 8$ & $137 ; 6$ \\
\hline \multirow{4}{*}{$\begin{array}{l}{ }^{\circ} \\
y \\
3 \\
3\end{array}$} & No & $55 \mid 59$ & $51 \mid 62$ & $43 \mid 57$ & $30 \mid 0$ & $59 \mid 60$ & $69 \mid 57$ & $59 \mid 72$ \\
\hline & Yes & $33 \mid 27$ & $28 \mid 21$ & $46 \mid 30$ & $69 \mid 0$ & $31 \mid 20$ & $24 \mid 29$ & $26 \mid 14$ \\
\hline & Retired & $12 \mid 14$ & $21 \mid 17$ & $11 \mid 13$ & $1 \mid 0$ & $10 \mid 20$ & $7 \mid 14$ & $15 \mid 14$ \\
\hline & $\mathrm{N}_{\text {valid; }} \%$ m.d. & $2190 ; 6$ & $536 ; 5$ & $683 ; 6$ & $70 ; 32$ & $98 ; 8$ & $662 ; 2$ & $141 ; 3$ \\
\hline \multirow{5}{*}{ 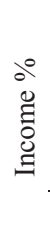 } & Below average & $45 \mid 52$ & $50 \mid 52$ & $58 \mid 62$ & $49 \mid 0$ & $11 \mid 25$ & $32 \mid 30$ & $51 \mid 29$ \\
\hline & No income & $38 \mid 33$ & $34 \mid 38$ & $18 \mid 20$ & $5 \mid 0$ & $60 \mid 50$ & $59 \mid 53$ & $45 \mid 64$ \\
\hline & Average & $15 \mid 14$ & $13 \mid 10$ & $21 \mid 17$ & $46 \mid 0$ & $25 \mid 25$ & $9 \mid 15$ & $2 \mid 7$ \\
\hline & Above average & $2 \mid 1$ & $3 \mid 0$ & $3 \mid 1$ & $0 \mid 0$ & $4 \mid 0$ & $0 \mid 3$ & $2 \mid 0$ \\
\hline & $\mathrm{N}_{\text {valid }} \%$ m.d. & $2124 ; 9$ & $509 ; 10$ & $676 ; 7$ & $73 ; 29$ & $87 ; 19$ & $639 ; 5$ & $140 ; 4$ \\
\hline
\end{tabular}

Legend: $H R$ Croatia, $H U$ Hungary, $X K$ Kosovo, $M K$ North Macedonia, $R O$ Romania, $S I$ Slovenia, $m . d$. missing data, $\sigma^{T}$ male, 우 female

offense. The lack of prior convictions simply means that he/she has not already been convicted of a crime, whereas the question of whether he/she has in fact previously committed a crime remains unanswered. In that sense the group of offenders with no prior convictions and/or prison experiences is far less informative (due to the many unknowns of the dark figure) than the group of offenders that has been convicted and/or spent time in prison. Prior convictions were in the BHS captured as general and specific recidivism, distinguishing between any criminal convictions and those due to having committed a violent criminal offense. The BHS also collected data on the offenders' prior imprisonment and the length of the time spent in prison.

As the relevant data shows (Table 5.8), out of all BHS offenders, more than one out of three has been convicted for a criminal offense prior to the (lethal) violence incident (general recidivism: 37.7\%), whereas almost one out of four has been convicted for a prior violent offense (specific recidivism: $23.7 \%$ ). For $40 \%$ of male offenders, general recidivism was found and for $26 \%$ special recidivism. Only for $20 \%$ of female violent offenders general and for $9 \%$ of them special recidivism was indicated in the case files. Only $5 \%$ of female BHS offenders served a prison sentence prior to the violent incident, whereas even $23 \%$ of the male BHS offenders had already spent time in prison. Now, from a preventive perspective, it would surely be interesting to investigate whether and how offenders with an already 
Table 5.8 BHS (lethal) violence offenders by type of recidivism, prior imprisonment, gender, and country (counting unit: offender)

\begin{tabular}{|c|c|c|c|c|c|c|c|c|}
\hline \multicolumn{2}{|l|}{$\%$} & $\begin{array}{c}\text { BHS } \\
\text { गैlo }\end{array}$ & $\begin{array}{l}\mathrm{HR} \\
\hat{\jmath}^{\prime} \mid{ }^{2} \\
\end{array}$ & $\begin{array}{l}\mathrm{HU} \\
\hat{\jmath}^{\prime} \mid \text { 保 } \\
\end{array}$ & $\begin{array}{l}\text { XK } \\
\text { गै|오 } \\
\end{array}$ & $\begin{array}{l}\text { MK } \\
\text { d’|우 }^{2}\end{array}$ & $\begin{array}{l}\text { RO } \\
\text { गैlo } \\
\end{array}$ & $\begin{array}{c}\text { SI } \\
\text { 이오 }\end{array}$ \\
\hline \multicolumn{2}{|c|}{ General recidivism } & $40 \mid 20$ & $36 \mid 18$ & $55 \mid 25$ & $11 \mid 0$ & $38 \mid 0$ & $34 \mid 14$ & $41 \mid 7$ \\
\hline \multicolumn{2}{|c|}{$\mathrm{N}_{\text {valid; }} \%$ m.d. } & $2202 ; 5$ & $530 ; 6$ & $685 ; 6$ & $71 ; 31$ & $105 ; 2$ & $668 ; 1$ & $143 ; 2$ \\
\hline \multicolumn{2}{|c|}{ Specific recidivism } & $26 \mid 9$ & $23 \mid 10$ & $34 \mid 11$ & $3 \mid 0$ & $23 \mid 0$ & $20 \mid 2$ & $34 \mid 7$ \\
\hline \multicolumn{2}{|c|}{$\mathrm{N}_{\text {valid }} ; \%$ m.d. } & $2137 ; 8$ & $524 ; 7$ & $681 ; 7$ & $64 ; 38$ & $101 ; 6$ & $624 ; 7$ & $143 ; 2$ \\
\hline \multirow{6}{*}{ 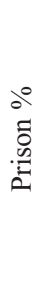 } & None & $77 \mid 95$ & $78 \mid 92$ & $72 \mid 94$ & $96 \mid 0$ & $74 \mid 100$ & $80 \mid 98$ & $75 \mid 100$ \\
\hline & $<1$ year & $6 \mid 2$ & $9 \mid 5$ & $4 \mid 1$ & $0 \mid 0$ & $12 \mid 0$ & $3 \mid 0$ & $8 \mid 0$ \\
\hline & $1-3$ years & $6 \mid 1$ & $5 \mid 0$ & $8 \mid 3$ & $0 \mid 0$ & $6 \mid 0$ & $5 \mid 0$ & $6 \mid 0$ \\
\hline & $3-5$ years & $4 \mid 1$ & $4 \mid 0$ & $4 \mid 1$ & $3 \mid 0$ & $2 \mid 0$ & $4 \mid 2$ & $1 \mid 0$ \\
\hline & $\geq 5$ years & $8 \mid 2$ & $3 \mid 3$ & $13 \mid 2$ & $2 \mid 0$ & $6 \mid 0$ & $8 \mid 0$ & $10 \mid 0$ \\
\hline & $\mathrm{N}_{\text {valid; }} \%$ m.d. & $2134 ; 8$ & $520 ; 8$ & $681 ; 7$ & $66 ; 36$ & $100 ; 7$ & $624 ; 7$ & $143 ; 2$ \\
\hline
\end{tabular}

Legend: $H R$ Croatia, $H U$ Hungary, $X K$ Kosovo, $M K$ North Macedonia, $R O$ Romania, $S I$ Slovenia, m.d. missing data, ơ male, 우 female

documented violent criminal history could be approached as a high-risk target group. The missing data problem is again most pronounced in case of the Kosovo sample, but again quite modest for all the other countries.

Among the factors commonly identified to be playing a major role in violent incidents, alcohol intoxication tempore criminis on the side of the offender might very well be the most prominent one. This is well reflected by the BHS findings in the Croatian, Hungarian, and Romanian samples, but strangely not as pronounced in the Slovenian sample, and appears almost irrelevant in the samples from Kosovo and North Macedonia, whereby the share of missing data cannot account for this country-specific difference (Table 5.9). We observe that male offenders are more frequently under the influence of alcohol during the (lethal) violent incident than female offenders. The BHS also collected data about offenders being under the influence of drugs tempore criminis, but with $5.3 \%$ of such offenders, this was found to be the exception ( $\mathrm{N}_{\text {valid }} 2073$; missings $10.7 \%$ ), especially when compared to the detected high share of alcohol intoxication ( $\mathrm{N}_{\text {valid }} 2104 ;{ }^{4}$ missings $9.3 \%$ ).

In those $18.2 \%$ of instances where offenders were found to have an addiction $\left(\mathrm{N}_{\text {valid }}\right.$ 1966; missing data $\left.15.3 \%\right)$, the vast majority of offenders suffered from an

\footnotetext{
${ }^{4}$ The discrepancy between the $\mathrm{N}_{\text {valid }}$ provided in the text (2104) and in Table 5.9 (2102) is the result of missing data on offenders' gender. This missing data problem regarding offenders' gender is most pronounced (again) in the Kosovo sample ( $\left.\mathrm{N}_{\text {missing }} 23\right)$, but few cases are found in the Croatian $\left(\mathrm{N}_{\text {missing }} 2\right)$ and Romanian samples ( $\left.\mathrm{N}_{\text {missing }} 1\right)$ as well. These missings however relate only to the cases involving one offender and one victim - for missing data on victims' gender in the total sample, see Table 5.11 and Appendix. The short case descriptions were not always fully conclusive in this respect, so out of consistency none of the missing gender values were corrected.
} 
Table 5.9 BHS (lethal) violence offenders by alcohol intoxication, gender, and country (counting unit: offender)

\begin{tabular}{|c|c|c|c|c|c|c|c|}
\hline Alcohol \% & $\begin{array}{l}\text { BHS } \\
\text { ठૈ|오 }\end{array}$ & $\begin{array}{l}\mathrm{HR} \\
\hat{\jmath}^{\prime} \mid \text { 足 }\end{array}$ & $\begin{array}{l}\mathrm{HU} \\
\text { गै|우 }\end{array}$ & $\begin{array}{l}\text { XK } \\
\text { गै|오 }\end{array}$ & $\begin{array}{l}\text { MK } \\
\text { ગૈ| }\end{array}$ & $\begin{array}{l}\text { RO } \\
\text { गै|우 }\end{array}$ & $\begin{array}{c}\text { SI } \\
\text { d’|P }\end{array}$ \\
\hline Yes & $47 \mid 36$ & $53 \mid 41$ & $50 \mid 34$ & $9 \mid 0$ & $9 \mid 0$ & $53 \mid 49$ & $33 \mid 13$ \\
\hline No & $53 \mid 64$ & $47 \mid 59$ & $50 \mid 66$ & $91 \mid 0$ & $91 \mid 100$ & $47 \mid 51$ & $67 \mid 87$ \\
\hline $\mathrm{N}_{\text {valid; }} \%$ m.d. & $2102 ; 9$ & $440 ; 22$ & $693 ; 5$ & $65 ; 37$ & $101 ; 6$ & $659 ; 2$ & $144 ; 1$ \\
\hline
\end{tabular}

Legend: $H R$ Croatia, $H U$ Hungary, $X K$ Kosovo, $M K$ North Macedonia, $R O$ Romania, $S I$ Slovenia, $m . d$. missing data, $\sigma^{\top 7}$ male, 우 female

alcohol addiction $(83.2 \%)$, followed by multiple substance addiction (8.8\%), hard drug addiction (5\%), and soft drug addiction (3\%).

The vast majority of offenders were citizens of the country where the (lethal) violence incident took place. This overlap in offender citizenship and country amounts to $100 \%$ in Kosovo, 99.1\% in North Macedonia, 95.7\% in Hungary, $95.4 \%$ in Croatia, and $91.8 \%$ in Slovenia $\left(\mathrm{N}_{\text {valid }} 2263\right.$; missing data $\left.2.5 \%\right)$. The remaining offender citizenships relate to relevant neighboring countries and largely reflect other citizenships as would be expected in the general population (e.g., Serbian and Bosnian in Croatia, Romanian in Hungary, Albanian in North Macedonia, Hungarian in Romania, Bosnian and Croatian in Slovenia). Foreign citizens obviously do not constitute a noticeable share of violent offenders in the BHS sample. However, citizenship captures only the formal belonging to a country in terms of citizenship, but not one's ethnicity.

Ethnicity is far more relevant throughout the region than an actual foreigner status in terms of foreign citizenship. Therefore, the BHS also collected information on offenders' ethnicity. Compared to the rest of Europe, where migrations and foreign citizens are frequently discussed in view of their role and share in crime, migration and foreigners play a far less prominent role in Southeastern Europe. As with citizenship, there is a significant overlap between the country of incident and the offenders' ethnicity in Kosovo (97.4\%), Hungary (88.7\%), Croatia (85.2\%), and Romania $(81.9 \%)$, but not in Slovenia $(67.8 \%)$ and North Macedonia $(51.4 \%)$. Nevertheless, the remaining ethnicities in these two countries, just like in those with a more obvious overlap, well reflect ethnic minorities that are found in the general population. It is however interesting that in Slovenia (11\%), Hungary $(7.7 \%)$, Romania (7.1\%), and North Macedonia (4.7\%), Roma and Sinti account for a quite significant share of ethnic minorities among violent offenders $\left(\mathrm{N}_{\text {valid }} 1865\right.$; missing data $19.6 \%$ ). 


\subsubsection{Male (Lethal) Violence}

In light of the just presented offender characteristics and bearing in mind all the discussed main incident features (Sect. 5.1), it is challenging to pick only one further topic for analysis. Since the number and share of female offenders in the BHS sample are rather small (Table 5.10), the following paragraphs will focus on male (lethal) violence. Not only do male offenders constitute the vast majority of offenders in the BHS sample, but also their particular distribution according to the type of violence and victim's gender seems to be of great importance for understanding the phenomenology of (the most frequent) violence in the Balkans.

Most BHS offenders are male and most BHS offenders engage in (lethal) violence against male victims (Table 5.10). As explained in the section's introductory methodological part, the data for this kind of analysis deals with $81 \%$ of the BHS offender sample ( $\mathrm{N} 1617)$. All cases involving more than one offender and/or more than one victim were dropped in order to avoid duplication/invention of non-existent offenders and/or victims. Male-on-male (lethal) violence is most expressed in the Romanian sample (the Kosovo sample displays considerably more missing data and thus only male offenders in a rather small sample), whereas male-on-female (lethal) violence is most frequent in the Hungarian sample (Table 5.10). The Hungary BHS sample also has an atypically high share of female offenders concerning both female-on-female and female-on-male (lethal) violence. There appears to be some sort of connection between the large share of female violent offenders and the large share of female victims. Further country-specific analysis should be able to detect its potential causes and provide explanations.

Analyzing (lethal) violence by offenders' and victims' gender and the type of violence $\left(\mathrm{N}_{\text {valid }} 1605\right.$; missing data $\left.0.7 \%\right)$, we find that in the BHS sample, male-onmale (lethal) violence presents itself mainly as other public (36.5\%) and other private violence $(29.5 \%)$, followed by bar $(11.8 \%)$ and thievery $(4.5 \%)$ violence. The remaining male-on-male (lethal) violence displays as work-related $(2.7 \%)$, neighborhood (2.6\%), enforcement (2.6\%), institutional (1.8\%), and separation violence

Table 5.10 BHS (lethal) violence offenders and victims by gender and country (counting unit: offender)

\begin{tabular}{|c|c|c|c|c|c|c|c|c|}
\hline \multicolumn{2}{|c|}{$\begin{array}{l}\text { offender | victim } \\
\text { by gender } \%\end{array}$} & \multirow{2}{*}{$\frac{\text { BHS }}{63}$} & \multirow{2}{*}{$\begin{array}{c}\text { HR } \\
70\end{array}$} & \multirow{2}{*}{$\begin{array}{c}\text { HU } \\
45\end{array}$} & \multirow{2}{*}{$\frac{\mathrm{XK}}{80}$} & \multirow{2}{*}{$\begin{array}{c}\text { MK } \\
73\end{array}$} & \multirow{2}{*}{$\frac{\mathrm{RO}}{71}$} & \multirow{2}{*}{$\begin{array}{l}\text { SI } \\
64\end{array}$} \\
\hline male & $\hat{\sigma} \mid \hat{\sigma}$ & & & & & & & \\
\hline violence & $\hat{o} \mid$ 우 & 25 & 19 & 37 & 20 & 20 & 21 & 25 \\
\hline \multirow{2}{*}{$\begin{array}{l}\text { female } \\
\text { violence }\end{array}$} & 이우 & 3 & 3 & 7 & 0 & 1 & 1 & 3 \\
\hline & 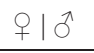 & 9 & 9 & 11 & 0 & 5 & 7 & 8 \\
\hline \multicolumn{2}{|c|}{$\mathrm{N}_{\text {valid; }} \%$ m.d. } & $1607 ; 1$ & $420 ; 1$ & $479 ; 0$ & $40 ; 11$ & $74 ; 1$ & $487 ; 0$ & $107 ; 0$ \\
\hline
\end{tabular}

Legend: $H R$ Croatia, $H U$ Hungary, $X K$ Kosovo, $M K$ North Macedonia, $R O$ Romania, $S I$ Slovenia, m.d. missing data, $\sigma^{\overparen{T}}$ male, 우 female 
$(1.7 \%)$, honor killings/blood feuds $(1.3 \%)$, discrimination violence $(1.2 \%)$, violence against police/guards $(1.1 \%)$, inheritance violence $(0.9 \%)$, renting $(0.6 \%)$ or drug-related violence $(0.5 \%)$, with the other types accounting for less than $0.5 \%$. In sharp contrast to this male-on-male type distribution, male-on-female violence mainly presents itself as other private $(55.5 \%)$ and separation $(22.7 \%)$ violence. This large share of other private (lethal) violence committed by male offenders toward female victims that is immediately followed by separation violence is very likely to indicate that in cases of private male-on-female violence we might actually be looking at domestic violence, potentially even intimate partner violence. Due to lack of more specific information on domestic disputes and/or separation conflicts in the short case descriptions, some of these cases very well might have been captured within the more general category of other private violence. The remaining types of male-on-female (lethal) violence are thievery $(8.3 \%)$ and other public $(8.1 \%)$ violence, with neighborhood $(1.5 \%)$, sex-market $(1.2 \%)$, enforcement $(0.7 \%)$, work-related $(0.7 \%)$, and bar $(0.5 \%)$ violence making up for approximately $5 \%$. The remaining types account for less than $0.5 \%$ each.

In contrast to the previously presented typology distribution of male (lethal) violence, female (lethal) violence presents itself mainly as other private violence $(33.3 \%)$, infanticides $(25.9 \%)$, thievery $(14.8 \%)$, other public $(4.3 \%)$ and enforcement $(3.7 \%)$ violence in case of female-on-female violence. However, female-onmale (lethal) violence predominantly displays as other private violence $(67.6 \%)$, infanticides $(10.1 \%)$, separation $(8.6 \%)$ and other public $(4.3 \%)$ violence, followed by bar $(2.2 \%)$ and thievery $(2.2 \%)$ violence. Interestingly, both male-on-female and female-on-male (lethal) violence in our sample presents itself in more than $75 \%$ of cases as other private and separation violence (male-on-female 78.2\%; female-onmale $76.2 \%$ ). This finding shows that both male and female offenders, when acting out violently toward the opposite gender, do this commonly in a private and/or intimate context. This might then indicate that, when it comes to domestic and/or intimate partner violence, both genders display a comparable propensity toward aggressive behavior, with the difference obviously being that males do this more frequently than females.

\subsection{Victim Characteristics}

After just having analyzed the main offender characteristics (Sect. 5.2), we now turn to the victims of (lethal) violence. This section will first briefly discuss the missing data issue which, when it comes to the victims of (lethal) violence in the BHS and compared to the other counting units, is much more pronounced (see Appendix). The challenges of merging the different databases with the victim database are in principle the same as when it comes to the offender database and same goes for the applied solutions to this challenge (Sect. 5.2). After these methodological introductions to the victim data, the section continues by providing first findings on main victim characteristics. This will be supplemented by analyzing potential risk factors for (lethal) victimization, especially victims' alcohol intoxication. 


\subsubsection{Missing Victim Data}

The victim variables (counting unit: victim N 2299) display a much wider range of the missing data problem as compared to the case and offender variables (Table 5.11 and Appendix), whereas the relationship databases (offender-offender relationship, victim-victim relationship, victim-offender relationship) were not analyzed at all due to the large share of missing data. The victim-offender relationship database was however used as a source of additional information in supplementing the short case descriptions if and when needed. Although quite tragic in terms of empirical research, the scope of missing data on different victim variables is nevertheless very insightful. It vividly depicts the lack of focus of criminal justice actors on the victims of (lethal) violence, at least if one agrees that the quantity and quality of information about victims (not) contained in case files might serve as a solid proxy for the (lack of) focus on the victims.

Clearly, the analyzed case files display a significant lack of information on victims' background such as education, parenthood, income, employment, addictions, and relationship status (Table 5.11). One might suspect that the lack of such data could also be due to poor data collection efforts during field work. However, this seems highly unlikely, especially when comparing the scope of missing data in the case and offender databases. To be more specific, suboptimal data collection during field work would be displayed as a constant feature throughout all databases (not only in the victim database) in the form of high missing values in most of the variables. This is however not the case with the other BHS databases in all of the sampled countries (exception: Kosovo sample). Due to the scope of missing data in the victim database, the following analysis will focus on those variables that display a less dramatic share of missing data.

Table 5.11 BHS (lethal) violence victim variables - share of missing data (counting unit: victim; N 2299)

\begin{tabular}{l|l|l|l|l|l}
\hline Variables & $\%$ m.d. & Variables & $\%$ m.d. & Variables & $\%$ m.d. \\
\hline Education & 55.4 & Affective & 14.3 & Injury severity & 3.0 \\
\hline Parenthood & 44.3 & Alcohol & 13.1 & Time of death & 2.8 \\
\hline Income & 38.1 & Age & 10.3 & Gender & 2.1 \\
\hline Employment & 31.2 & Nationality & 9.5 & VO relationship & 1.9 \\
\hline Addiction & 29.2 & Cruelty & 5.9 & Type & 0.1 \\
\hline Relationship & 28.6 & Sexual & 5.4 & Motive & 0.0 \\
\hline Ethnicity & 26.1 & Residence & 5.3 & & \\
\hline Drugs & 15.4 & Public official & 4.2 & & \\
\hline
\end{tabular}

Legend: $m . d$. missing data 


\subsubsection{General Victim Characteristics}

BHS victims of (lethal) violence in terms of gender are predominantly male and account for $88.7 \%$ of all BHS victims, and the two largest age groups of male victims are 30-40 and 20-30 years compared to the two largest age groups of female victims who are 40-50 and 30-40 years (Fig. 5.8). Comparable to the female offenders' age curve (Fig. 5.7), we again observe a slightly older age curve for female victims than for male victims (Fig. 5.8). A similar age curve in view of gender differences is found in the sample countries, again with the exception of Hungary, where just like in case of the female offenders, we find a significantly higher share of female victims $(43.5 \%)$ than in all the other BHS countries, where the share of female victims ranges from $16.7 \%$ to $29.7 \%$ (Table 5.12).

In terms of particularly vulnerable groups of victims, it appears that especially older women aged 70 years and more make up a considerable share of victims of (lethal) violence. Interestingly, in the BHS sample, infants and young children appear far less exposed to (lethal) violence than the elderly. This might reflect a generally rather old population in the BHS countries with low birth rates, but further national research would be needed in order to make firm statements.

Most victims (84.3\%; $\left.\mathrm{N}_{\text {valid }} 2177\right)$ just like most offenders $\left(80.4 \%\right.$; $\left.\mathrm{N}_{\text {valid }} 2234\right)$ come from the same place where the offence was committed, which also means that in most cases, the victim and the offender come from the same place. Only exceptionally is the victim a public official targeted by the violent incident in relation to his/her duty. Looking at the severity of the injuries inflicted upon the victims in the course of the violent incident, we observe that more than $3 / 4$ of victims suffered heavy bodily injuries $(42.7 \%)$ or death $(34.8 \%)$, compared to only less than onefourth of victims who suffered light bodily injuries $(16.5 \%)$ or no injuries at all (6.1\%) $\left(\mathrm{N}_{\text {valid }} 2229\right)$. These findings show that at least on this overall level, the severity of the victims' injuries is no proxy for (potential) lethality of the violent incident, since the overall ratio of completed vs. attempted homicides among victims is 39.7 vs $57.4\left(\mathrm{~N}_{\text {valid }} 2234\right)$. In other words, if attempted homicides were to be regarded as instances of less severe violence inflicted upon the victim, then the share of light
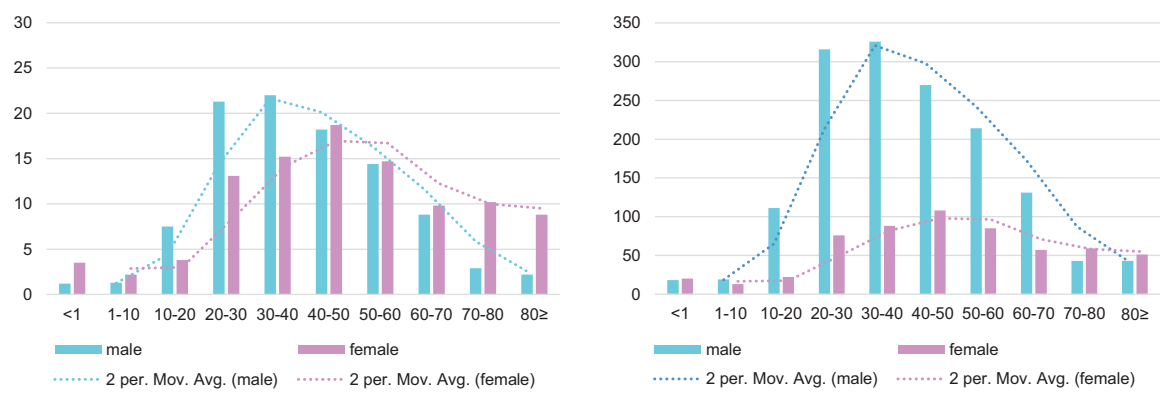

Fig. 5.8 BHS (lethal) violence victims by gender and age groups in victim numbers (left) and as shares within gender (right) (counting unit: victims; $\mathrm{N}_{\text {valid }} 2059 ; 10.4 \%$ missing data) 
Table 5.12 BHS (lethal) violence victims by age groups, gender, and country (counting unit: victim)

\begin{tabular}{|c|c|c|c|c|c|c|c|}
\hline Age groups \% & $\begin{array}{c}\text { BHS } \\
\text { ㅊ|우 }\end{array}$ & $\begin{array}{l}\mathrm{HR} \\
\text { गे|우 }^{2}\end{array}$ & $\begin{array}{l}\mathrm{HU} \\
\text { 히오 }\end{array}$ & 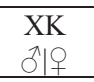 & $\begin{array}{l}\text { MK } \\
\text { 히오 }\end{array}$ & $\begin{array}{l}\mathrm{RO} \\
\text { 히오 }\end{array}$ & $\begin{array}{c}\text { SI } \\
\lambda^{\lambda} \mid \text { I }\end{array}$ \\
\hline$<1$ & $1 \mid 4$ & $2 \mid 6$ & $2 \mid 4$ & $0 \mid 0$ & $1 \mid 4$ & $1 \mid 2$ & $0 \mid 0$ \\
\hline $1-10$ & $1 \mid 2$ & $0.4 \mid 2$ & $4 \mid 3$ & $0 \mid 0$ & $1 \mid 0$ & $0.4 \mid 1$ & $2 \mid 4$ \\
\hline $10-20$ & $8 \mid 4$ & $5 \mid 1$ & $9 \mid 6$ & $18 \mid 0$ & $6 \mid 7$ & $8 \mid 3$ & $8 \mid 0$ \\
\hline $20-30$ & $21 \mid 13$ & $23 \mid 13$ & $10 \mid 11$ & $32 \mid 22$ & $33 \mid 7$ & $26 \mid 16$ & $18 \mid 16$ \\
\hline $30-40$ & $22 \mid 15$ & $25 \mid 17$ & $16 \mid 12$ & $14 \mid 44$ & $22 \mid 15$ & $23 \mid 17$ & $30 \mid 16$ \\
\hline $40-50$ & $18 \mid 19$ & $20 \mid 17$ & $18 \mid 18$ & $22 \mid 11$ & $13 \mid 26$ & $17 \mid 19$ & $18 \mid 24$ \\
\hline $50-60$ & $14 \mid 15$ & $12 \mid 17$ & $21 \mid 15$ & $12 \mid 11$ & $17 \mid 4$ & $12 \mid 15$ & $14 \mid 13$ \\
\hline $60-70$ & $9 \mid 10$ & $8 \mid 6$ & $13 \mid 9$ & $0 \mid 11$ & $6 \mid 19$ & $9 \mid 12$ & $9 \mid 13$ \\
\hline $70-80$ & $3 \mid 10$ & $4 \mid 9$ & $4 \mid 12$ & $2 \mid 0$ & $0 \mid 15$ & $3 \mid 9$ & $0 \mid 7$ \\
\hline $80 \geq$ & $2 \mid 9$ & $2 \mid 11$ & $4 \mid 10$ & $0 \mid 0$ & $1 \mid 4$ & $2 \mid 7$ & $2 \mid 7$ \\
\hline $\mathrm{N}_{\text {valid; }} \%$ m.d. & $2059 ; 10$ & $576 ; 5$ & $583 ; 17$ & $58 ; 39$ & $106 ; 25$ & $589 ; 1$ & $147 ; 5$ \\
\hline
\end{tabular}

Legend: $H R$ Croatia, $H U$ Hungary, $X K$ Kosovo, $M K$ North Macedonia, $R O$ Romania, SI Slovenia, m.d. missing data, $\sigma^{\top 7}$ male, 우 female

and no bodily injuries suffered by the victims (22.6\%) should be much closer to $60 \%$ (approx. share of attempted homicides) or at least far more pronounced. Similarly, when looking at the time of death of the victims in the BHS sample, we observe that a rather large share of killed victims did not die on the spot and during the violent incident itself, but later on (29\%; $\left.\mathrm{N}_{\text {valid }} 2234\right)$. Based on both findings, it (again) seems plausible to study completed as well as attempted homicides more comprehensively as one phenomenon, ideally by also including other types of nonhomicidal (lethal) violent crime (e.g., aggravated assault or rape with and without fatal outcome).

Slightly more victims of (lethal) violence in the BHS sample are in a relationship $(52.8 \%)$ than those who are single $(45.7 \%)$, with the majority of those that are in a relationship being married $\left(\mathrm{N}_{\text {valid }} 1641\right)$. However, since the share of missing data for this variable (28.6\%), just as for other similar victims' background variables, is rather high (Table 5.11, Appendix), it does not seem justified to base further analysis on these findings. Therefore, the last topic in the victim characteristics section will focus on the influence of alcohol intoxication tempore criminis in an attempt to check for potential risk factors.

\subsubsection{Victimization and Victim-Offender Alcohol Intoxication}

Unsurprisingly, when looking at victims' alcohol intoxication by the type of (lethal) violence, we find the highest share of intoxicated victims within bar violence, where $69 \%$ of victims were under the influence of alcohol tempore criminis. Now, 
differentiating between lethal and non-lethal violence in light of victims' alcohol intoxication, we see that in the total BHS sample, male victims are slightly more often under the influence of alcohol in case of completed homicides, and male victims are generally far more often under the influence of alcohol than female victims (Table 5.13). On the different country levels, there also seems to be a slightly higher share of intoxicated victims (especially male ones) among those who died due to the violent incident (Table 5.13). Based on first analysis and without further information, one can only speculate about the existence of actual correlations, let alone causal relations. Whether victims' alcohol intoxication is in fact a potential risk factor in view of the deadliness of the incident or not would need to be firmly established before one can further investigate how this risk factor might be working. Could it be that intoxicated victims are more helpless and less able to defend themselves in the event of a violent incident, or might it be that intoxicated victims are more likely to get involved, perhaps even provoke, a potentially deadlier violent incident? How could these questions even be empirically investigated and further explored?

Clearly, the impact of victims' alcohol intoxication tempore criminis cannot be analyzed, let alone understood correctly, outside of the context of the whole violent incident, which obviously includes the offender. Analyzing the potential impact of alcohol on the deadliness of the violent incident, we checked for differences between completed and attempted homicides depending on victim and/or offender intoxication (Table 5.14). We also analyzed alcohol intoxication in view of the gender variable for the most frequent victim-offender constellation (male-on-male) while distinguishing between lethal and non-lethal violence and for all the BHS countries (Table 5.15).

Table 5.13 BHS (lethal) violence victims by alcohol intoxication, gender, country, and (completed) homicide (counting unit: victim)

\begin{tabular}{|c|c|c|c|c|c|c|c|c|}
\hline \multicolumn{2}{|c|}{ Alcohol intoxication $\%$} & $\begin{array}{l}\text { BHS } \\
\text { 이우 }\end{array}$ & $\begin{array}{l}\text { HR } \\
\text { 이우 }\end{array}$ & $\begin{array}{l}\mathrm{HU} \\
\text { 이우우 }\end{array}$ & $\begin{array}{l}\mathrm{XK} \\
^{\prime}{ }^{\prime} \mid \text { 우 }\end{array}$ & $\begin{array}{l}\text { MK } \\
\text { 히우 }\end{array}$ & $\begin{array}{l}\text { RO } \\
\text { 이우 }\end{array}$ & \begin{tabular}{|l} 
SI \\
지이우
\end{tabular} \\
\hline \multirow{2}{*}{ Completed } & Yes & 46115 & 46113 & $49 \mid 15$ & $17 \mid 0$ & $13 \mid 10$ & $65 \mid 23$ & 1018 \\
\hline & No & $54 \mid 85$ & 54187 & 51185 & $83 \mid 100$ & 87190 & 35177 & $90 \mid 92$ \\
\hline \multirow[t]{2}{*}{ Attempted } & Yes & $37 \mid 12$ & $43 \mid 14$ & $42 \mid 13$ & 010 & 010 & $39 \mid 12$ & $30 \mid 10$ \\
\hline & No & 63188 & $57 \mid 86$ & 58187 & $100 \mid 100$ & $100 \mid 100$ & $61 \mid 88$ & $70 \mid 90$ \\
\hline \multicolumn{2}{|l|}{$\mathrm{N}_{\text {valid }} ; \%$ m.d. } & $1994 ; 11$ & $413 ; 32$ & $692 ; 2$ & $65 ; 8$ & $80 ; 33$ & $591 ; 1$ & $153 ; 1$ \\
\hline
\end{tabular}

Legend: $H R$ Croatia, $H U$ Hungary, $X K$ Kosovo, $M K$ North Macedonia, RO Romania, $S I$ Slovenia, $m . d$. missing data, $\sigma^{7}$ male, 우 female

Table 5.14 BHS (lethal) violence victims and offenders by alcohol intoxication and (completed) homicide (counting unit: victim/offender; $\mathrm{N}_{\text {valid }} 1389$; missing data $14.1 \%$ )

\begin{tabular}{l|l|l|l|l}
\hline $\begin{array}{l}\text { Homicide } \\
\%\end{array}$ & $\begin{array}{l}\text { Victim and offender } \\
\text { intoxicated }\end{array}$ & $\begin{array}{l}\text { Neither victim nor } \\
\text { offender intoxicated }\end{array}$ & $\begin{array}{l}\text { Only offender } \\
\text { intoxicated }\end{array}$ & $\begin{array}{l}\text { Only victim } \\
\text { intoxicated }\end{array}$ \\
\hline Completed & 33.4 & 45.4 & 14.2 & 7.1 \\
\hline Attempted & 31.3 & 42.3 & 20.9 & 5.5 \\
\hline
\end{tabular}


Table 5.15 BHS victims of male-on-male (attempted) homicide by alcohol intoxication and country (counting unit: victim)

\begin{tabular}{|c|c|c|c|c|c|c|c|}
\hline Homicide \% & $\begin{array}{l}\text { BHS } \\
\text { YIN }\end{array}$ & $\begin{array}{l}\text { HR } \\
\text { YIN }\end{array}$ & $\begin{array}{l}\text { HU } \\
\text { YIN }\end{array}$ & $\begin{array}{l}\text { XK } \\
\text { YIN }\end{array}$ & $\begin{array}{l}\text { MK } \\
\text { YIN }\end{array}$ & $\begin{array}{l}\text { RO } \\
\text { YIN }\end{array}$ & $\begin{array}{l}\text { SI } \\
\text { YIN }\end{array}$ \\
\hline Completed & $57 \mid 43$ & $54 \mid 46$ & 68132 & 33167 & $17 \mid 83$ & 71129 & $12 \mid 88$ \\
\hline Attempted & 42158 & $50 \mid 50$ & $52 \mid 48$ & $0 \mid 100$ & 01100 & 40160 & 32168 \\
\hline $\mathrm{N}_{\text {valid }} ; \%$ m.d. & $876 ; 13$ & $194 ; 34$ & $209 ; 2$ & $30 ; 6$ & $36 ; 33$ & $341 ; 1$ & $66 ; 3$ \\
\hline
\end{tabular}

Legend: $H R$ Croatia, $H U$ Hungary, $X K$ Kosovo, $M K$ North Macedonia, $R O$ Romania, $S I$ Slovenia, $Y$ alcohol intoxicated, $N$ not alcohol intoxicated, m.d. missing data

Findings (Table 5.14) indicate that there is no apparent difference between the constellations when both victim and offender are alcohol intoxicated as opposed to when neither of them is intoxicated, at least with regard to the share of such constellations within cases of completed and attempted homicides. However, when looking at those violent incidents where only the victim or only the offender is alcohol intoxicated, the findings show that offender intoxication is more frequently found among completed homicides, whereas victim intoxication is more frequently found among attempted homicides. BHS findings (Table 5.15) also show that there is a considerable country-specific difference when it comes to victims' alcohol intoxication in case of male-on-male (lethal) violence, both with regard to the share of (non) intoxication and (non)lethality of the incident. Looking at the total BHS sample, we see that in case of completed male-on-male homicides, almost $60 \%$ of victims were under the influence of alcohol. This ratio is almost exactly inverted in case of attempted male-on-male homicides, where almost $60 \%$ of victims were not under the influence of alcohol. However, looking at the country findings, we see strong variations both in share and distribution of alcohol intoxication. In light of this and considering the actual sample size that covers $81 \%$ of victims and offenders (oneon-one incidents), the findings are not fully conclusive and further analysis is obviously needed, especially in order to account for the detected country-specific variations.

\subsection{Procedural Characteristics}

In this section, (lethal) violence is analyzed from a procedural and normative perspective. This puts the focus on offenders of (lethal) violence and how they are handled by the criminal justice system. The criminal justice system includes the police, the prosecution, and the courts. The findings deal with various procedural characteristics of criminal prosecutions and trails and also relevant trial outcomes and sentencing decisions. The goal of this line of inquiry has been to decipher the how, perhaps even some of the why, of the normative construction of (lethal) violence. However, first findings allow only for a very general impression of the main procedural characteristics. In order to further analyze and fully understand them, 
in-depth country-specific analyses are needed. Nevertheless, even the first general findings seem extremely valuable, especially in view of the lack of comparable previous research in the countries of interest.

\subsubsection{Missing Procedural Data}

Most of the procedural data (counting unit: offender or case) displays low or modest missing data ranges (Appendix). When looking at the case-based procedural variables, we find less than 5\% missing data in 13 variables and less than $10 \%$ missing data in 7 variables, and the remaining 7 variables display high missings due to the dropout of cases throughout the criminal procedure and therefore are no actual issues of missing data. A slightly higher occurrence of missing data is found in the offender-based procedural variables, where the majority of variables displays missing data between $5 \%$ and $10 \%$ (15 variables), 5 variables less than $15 \%$ missing data, and 4 variables less than $20 \%$ missing data.

\subsubsection{Detection of (Lethal) Violence}

Most frequently, the BHS incidents came to the attention of the police on the basis of a witness call/report $(64.5 \%)$ or hospital/physician's report (13.2\%). Incidents also got reported to the police by the offender $(6 \%)$ or a body was found $(5 \%)$, while incidents rarely got reported by the victim (1.6\%) (counting unit: case; $\mathrm{N}_{\text {valid }} 1933$; missing data $3.2 \%$ ). The vast majority of incidents, once reported to the police, were prosecuted (93.9\%) and extremely rarely dismissed by the prosecution $(6.1 \%)$ (counting unit: case; $\mathrm{N}_{\text {valid }} 1952$; missing data $2.3 \%$ ). If, however, dismissed, then this was mainly due to lack of evidence, the offender's death, or self-defense constellations.

\subsubsection{Detention and Criminal Procedure}

Most BHS offenders were detained at some point during the duration of the criminal procedure which followed the (lethal) violent incident. Almost $79 \%$ of all BHS offenders were detained (counting unit: offender; $\mathrm{N}_{\text {valid }} 2227$ ), whereby detention lasted between 1 and 2251 days (mean 425; median 308; std. deviation 390). The average length of criminal procedure, capturing the time period from the incident being reported to the police until the final adjudication in court, is 36 months in case of completed and 27 months in case of attempted homicides (Table 5.16). Interestingly, the average length of criminal procedure is usually longer in case of female offenders and in case of completed homicides in Croatia, Hungary, Kosovo, 
Table 5.16 BHS procedural characteristics of (attempted) homicides by gender and country (counting unit: offender)

\begin{tabular}{|c|c|c|c|c|c|c|c|c|c|}
\hline & $\begin{array}{l}\text { BHS } \\
\text { 히우 }\end{array}$ & $\begin{array}{l}\mathrm{HR} \\
\text { 지우 }\end{array}$ & $\begin{array}{l}\mathrm{HU} \\
^{\prime}{ }^{\prime} \mid ㅇ ㅜ\end{array}$ & $\begin{array}{l}\text { XK } \\
\text { 지이우 }\end{array}$ & $\begin{array}{l}\text { MK } \\
\text { 지우 }\end{array}$ & $\begin{array}{l}\text { RO } \\
\text { 지이우 }\end{array}$ & $\begin{array}{c}\text { SI } \\
\text { 지우우 }\end{array}$ \\
\hline \multirow{2}{*}{\multicolumn{2}{|c|}{$\begin{array}{l}\text { Average length of } \\
\text { procedure in } \\
\text { months }\left(\mathrm{N}_{\text {valid }}\right. \\
2096 ; 10 \% \text { m.d.) }\end{array}$}} & $U$ & 37130 & $54 \mid 36$ & 43129 & 3910 & 5519 & $12 / 29$ & $25 \mid 40$ \\
\hline & & $\varangle$ & 27125 & 40132 & $31 \mid 27$ & 2510 & $39 \mid 13$ & 16114 & $24 \mid 26$ \\
\hline \multirow{6}{*}{$\begin{array}{l}\text { Offender } \\
\text { pleas in } \% \\
\left(\mathrm{~N}_{\text {valid }} 2126 ;\right. \\
7 \% \text { m.d. })\end{array}$} & \multirow{3}{*}{$u$} & Guilty & $58 \mid 56$ & $40 \mid 52$ & 63160 & 8710 & $32 \mid 50$ & 75150 & $34 \mid 25$ \\
\hline & & $\begin{array}{l}\text { Not } \\
\text { guilty }\end{array}$ & $34 \mid 38$ & $52 \mid 40$ & 35137 & 1310 & $64 \mid 50$ & 8131 & 53175 \\
\hline & & Silent & 816 & 818 & 313 & $0 \mid 0$ & $5 \mid 0$ & 1719 & 1310 \\
\hline & \multirow{3}{*}{$\varangle$} & Guilty & 51151 & 29125 & $61 \mid 64$ & 8810 & 1910 & 58158 & 58175 \\
\hline & & $\begin{array}{l}\text { Not } \\
\text { guilty }\end{array}$ & 38140 & 65169 & 37131 & 1210 & 751100 & 20119 & 41125 \\
\hline & & Silent & 1119 & 616 & 214 & 010 & 610 & $22 \mid 23$ & 210 \\
\hline \multirow{2}{*}{\multicolumn{2}{|c|}{$\begin{array}{l}\text { Convicted offenders } \\
\text { in } \%\left(\mathrm{~N}_{\text {valid }} 2152 ;\right. \\
6 \% \text { m.d.) }\end{array}$}} & $u$ & 90189 & 79178 & 91191 & $100 \mid 0$ & 761100 & 99194 & $90 \mid 100$ \\
\hline & & $\varangle$ & 90179 & 79169 & 91181 & 9510 & 831100 & 98196 & 81156 \\
\hline \multirow{2}{*}{\multicolumn{2}{|c|}{$\begin{array}{l}\text { Prison sentence in } \\
\%\left(\mathrm{~N}_{\text {valid }} 1915 ;\right. \\
0 \% \text { m.d. })\end{array}$}} & U & 98195 & 97171 & 99199 & 9510 & $89 \mid 100$ & $100 \mid 100$ & $100 \mid 100$ \\
\hline & & $\ll$ & 98194 & $96 \mid 96$ & $100 \mid 94$ & 9710 & $94 \mid 100$ & 981100 & 98160 \\
\hline \multirow{2}{*}{\multicolumn{2}{|c|}{$\begin{array}{l}\text { Prison sentence } \\
\text { suspended in } \% \\
\left(\mathrm{~N}_{\text {valid }} 1885 ; 2 \% \text { m.d. }\right)\end{array}$}} & $U$ & 319 & 8124 & 217 & $0 \mid 0$ & 010 & 217 & 210 \\
\hline & & $\varangle$ & $15 \mid 26$ & 8121 & 7127 & 010 & 3133 & 25129 & $21 \mid 25$ \\
\hline \multirow{2}{*}{\multicolumn{2}{|c|}{$\begin{array}{l}\text { Harsh sentence in } \% \\
\left(\mathrm{~N}_{\text {valid }} 1859 ; 3 \% \text { m.d. }\right)\end{array}$}} & $U$ & 2317 & 21117 & 2616 & 4610 & 510 & 1117 & 6210 \\
\hline & & $\ll$ & 212 & 110 & 510 & $0 \mid 0$ & $0 \mid 33$ & 110 & 2133 \\
\hline \multirow{2}{*}{\multicolumn{2}{|c|}{$\begin{array}{l}\text { Average sentence } \\
\text { length in months } \\
\left(\mathrm{N}_{\text {valid }} 1859 ; 3 \% \text { m.d. }\right)\end{array}$}} & U & $173 \mid 128$ & $147 \mid 139$ & $203 \mid 132$ & $174 \mid 0$ & $125 \mid 108$ & $148 \mid 120$ & 216183 \\
\hline & & $\varangle$ & 63156 & 39128 & $105 \mid 80$ & 2510 & 74152 & 56147 & $50 \mid 90$ \\
\hline
\end{tabular}

Legend: $H R$ Croatia, $H U$ Hungary, $X K$ Kosovo, $M K$ North Macedonia, $R O$ Romania, $S I$ Slovenia, $m . d$. missing data, $\sigma^{\top}$ male, 우 female, $A$ attempted homicide, $C$ completed homicide

and Macedonia, while criminal proceedings are much shorter in Romania and Slovenia, where in case of female offenders, proceedings are longer and the difference between attempted vs. completed homicides is less pronounced or even goes in favor of the completed homicide proceedings. It does not appear as if this average length of procedure is related directly to how the offenders plea in these countries. A considerable share of BHS offenders plead guilty, both in case of attempted and in completed homicides, and in case of both genders, with Slovenia having the lowest share of guilty pleas and Romania one of the highest. 
The court proceedings commonly result in a conviction, whereas those offenders who are not convicted are rarely acquitted or charges against them dismissed. They are mainly found insane and committed to a psychiatric institution. Convictions are high for both completed and attempted homicides, whereby convictions almost exclusively result in a prison sentence (Table 5.16). Just as the prison sentence is more often suspended in case of attempted homicides, so is the issued prison sentence in case of completed homicides more often a harsh one. In this respect, a harsh prison sentence implies a long-term prison sentence. The average sentence in case of completed homicides is much longer (mean 167; median 144; std. deviation 105) than in case of attempted homicides (mean 62; median 48; std. deviation 54). Nevertheless, the still rather high sentences in case of attempted homicides indicate that these incidents are quite severe, even though they have not resulted in the death of the victim(s).

Clearly the previously provided first findings present but a fraction of the BHS procedural data which will also need to be further analyzed, both in light of specific national (normative) contexts and in light of different incident, offender, and victim characteristics. Thus far, we did not analyze the normative (re)construction of (lethal) violence by different criminal justice agencies. This means that the BHS's first line of inquiry into the "power to define violence" still remains open and is in need of further analysis (and data sourced from police files) by taking a much broader approach to (lethal) violence that also includes non-homicidal (lethal) violence.

\section{References}

Allison, P. D. (2002). Missing data. Thousand Oaks: Sage.

Botrić, V. (2011). Structural unemployment and its determinants in Southeast Europe. Ekonomska Misao i Praksa, 1, 81-100.

German Federal Foreign Office. (2020, January 31). Working together to stop illegal arms trade in the Western Balkans. https://www.auswaertiges-amt.de/en/aussenpolitik/themen/abruestung/ uebersicht-konvalles-node/-/2118584. Accessed 2 Nov 2020.

Grillot, S. R. (2010). Guns in the Balkans: Controlling small arms and light weapons in seven Western Balkan countries. Southeast European and Black Sea Studies, 10(2), 147-171.

Jovanović, B., Dojčinović, S., \& Đokić, S. (2020, May 5). Bad blood: A war between Montenegrin cocaine clans engulfs the Balkans. https://www.occrp.org/en/balkan-cocaine-wars/a-warbetween-montenegrin-cocaine-clans-engulfs-the-balkans. Accessed 2 Nov 2020.

Liem, M., \& Oberwittler, D. (2012). Homicide followed by suicide in Europe. In M. Liem \& W. Pridemore (Eds.), Handbook of European homicide research (pp. 197-215). New York: Springer.

Mucchielli, L. (2012). Homicides in contemporary France. In M. Liem \& W. Pridemore (Eds.), Handbook of European homicide research (pp. 301-312). New York: Springer.

Riedel, M., \& Regoeczi, W. C. (2004). Missing data in homicide research. Homicide Studies, 8(3), 163-192.

Spierenburg, P. (2012). Long-term historical trends of homicide in Europe. In M. Liem \& W. Pridemore (Eds.), Handbook of European homicide research (pp. 25-38). New York: Springer. 
Stamatel, J. P. (2012). The effects of political, economic, and social changes on homicide. In M. Liem \& W. Pridemore (Eds.), Handbook of European homicide research (pp. 155-170). New York: Springer.

UNODC. (2019). Global study on homicide 2019, Booklet 1: Executive summary. Vienna: UNODC.

UNODC. (2020). UNODC South Eastern Europe on organized crime. https://www.unodc.org/ southeasterneurope/en/organized-crime/index.html. Accessed 2 Nov 2020.

Open Access This chapter is licensed under the terms of the Creative Commons Attribution 4.0 International License (http://creativecommons.org/licenses/by/4.0/), which permits use, sharing, adaptation, distribution and reproduction in any medium or format, as long as you give appropriate credit to the original author(s) and the source, provide a link to the Creative Commons license and indicate if changes were made.

The images or other third party material in this chapter are included in the chapter's Creative Commons license, unless indicated otherwise in a credit line to the material. If material is not included in the chapter's Creative Commons license and your intended use is not permitted by statutory regulation or exceeds the permitted use, you will need to obtain permission directly from the copyright holder.

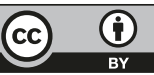

